\title{
Article \\ Coaxiality Optimization Analysis of Plastic Injection Molded Barrel of Bilateral Telecentric Lens
}

\author{
Chao-Ming Lin *D and Yun-Ju Chen \\ Department of Mechanical and Energy Engineering, National Chiayi University, Chiayi 600355, Taiwan; \\ s1053155@alumni.ncyu.edu.tw \\ * Correspondence: cmlin@mail.ncyu.edu.tw
}

\begin{abstract}
Plastic optical components are light in weight, easy to manufacture, and amenable to mass production. However, plastic injection molded parts are liable to shrinkage and warpage as a result of the pressure and temperature variations induced during the molding process. Consequently, controlling the process parameters in such a way as to minimize the geometric deformation of the molded part and improve the performance of the optical component as a result remains an important concern. The present study considered the problem of optimizing the injection molding parameters for the plastic lens barrel of a bilateral telecentric lens (BTL) containing four lens assemblies. The study commenced by using CODE V optical software to design the lens assemblies and determine their optimal positions within the barrel. Taguchi experiments based on Moldex3D simulations were then performed to determine the processing conditions (i.e., maximum injection pressure, maximum packing pressure, melt temperature, mold temperature, and cooling time) which minimize the coaxiality of the plastic barrel. Finally, CODE V and grayscale analyses were performed to confirm the optical performance of the optimized BTL. The Taguchi results show that the coaxiality of the plastic lens barrel is determined mainly by the maximum packing pressure and melt temperature. In addition, the CODE V and grayscale analysis results confirm that the optimized BTL yields a better modulus transfer function, spot diagram performance, and image quality than a BTL produced using the general injection molding parameters.
\end{abstract}

Keywords: injection molding; concentricity; coaxiality; optical barrel; bilateral telecentric lens; optimization

Bilateral Telecentric Lens. Symmetry

2022, 14, 200. https://doi.org/

$10.3390 /$ sym 14020200

Academic Editor: Emanuel Willert

Received: 18 December 2021

Accepted: 18 January 2022

Published: 20 January 2022

Publisher's Note: MDPI stays neutral with regard to jurisdictional claims in published maps and institutional affiliations.

Copyright: () 2022 by the authors Licensee MDPI, Basel, Switzerland. This article is an open access article distributed under the terms and conditions of the Creative Commons Attribution (CC BY) license (https:// creativecommons.org/licenses/by/ $4.0 /)$.

\section{Introduction}

Plastic provides an ideal material for the fabrication of optoelectronic product accessories and supports due to its light weight, low cost, high mechanical strength, ease of processing, and good potential for mass production. However, the successful realization of plastic optical components involves many challenges, including optical design, integrated mechanism design, process parameter design, and product inspection and analysis. Plastic optical products are commonly fabricated using injection molding. However, while injection molding has significant advantages in terms of a high throughput, a low unit cost, and good repeatability, the quality of the molded components is extremely sensitive to the processing conditions, e.g., the injection pressure, packing pressure, melt temperature, mold temperature, packing time, and cooling time. Moreover, the processing parameters have both individual and interactive effects on the molding outcome. Consequently, determining the processing conditions which optimize the quality of the molded products (the dimensional tolerance, surface finish, mechanical strength, etc.) is extremely complex.

Optical components are subject to extremely tight manufacturing tolerances in order to achieve the necessary imaging quality. However, achieving these tolerances for plastic components realized through injection molding is extremely challenging, particularly in the case of geometric assemblies with high aspect ratios, or non-symmetrical geometries [1-4]. 
In many lens-based devices, the lens assemblies are housed within plastic bodies, and hence the problem of ensuring the imaging quality of the device involves not only guaranteeing the optical quality of the individual lenses, but also controlling the geometrical precision and form of the housing. For example, for bilateral telecentric lenses (BTLs), which are designed to provide a constant field of view (FOV) at all distances from the lens, roundness or concentricity errors of the lens barrel result in misalignments of the lens assemblies, which then seriously degrade the performance of the device. As a result, it is essential that the molding parameters are correctly controlled in such a way as to minimize the shrinkage, warpage, and residual stress of the barrel during the manufacturing process [5-7].

Many studies have demonstrated the feasibility of combining the Taguchi experimental method with mold flow simulations to determine the optimal injection molding processing parameters through a minimum number of experiential trials [8-11]. Furthermore, many software systems and algorithms have been applied to evaluate existing optical designs, optimize the performance of new imaging solutions, reduce manufacturing costs through process improvements, etc. [12-17]. Among the many optical design software packages currently available, CODE V (Synopsys, Inc., Mountain View, California, USA) is one of the most commonly used for the design, tolerancing, and performance evaluation of new optical configurations.

In the present study, a hybrid Taguchi/Moldex3D simulation approach was employed to optimize the injection molding processing parameters for the plastic lens barrel of the BTL device shown in Figure 1 consisting of four lenses and a protruding handle. Optimal analysis of plastic injection molding was based on the authors' previous research on the roundness and concentricity of the BTL [18]. The authors performed further optical analysis on the concentricity results to confirm the optimized results. CODE V optical software was first used to design the four lenses and to determine their optimal positions within the barrel. Taguchi/Moldex3D simulations were then performed to establish the injection molding conditions which minimize the coaxiality error of the lens barrel (i.e., the overall concentricity error of the four lenses) following the molding process. Finally, CODE V and grayscale analyses were performed to investigate the modulus transfer function (MTF), spot diagram characteristics, and imaging performance of the optimized BTL barrel.

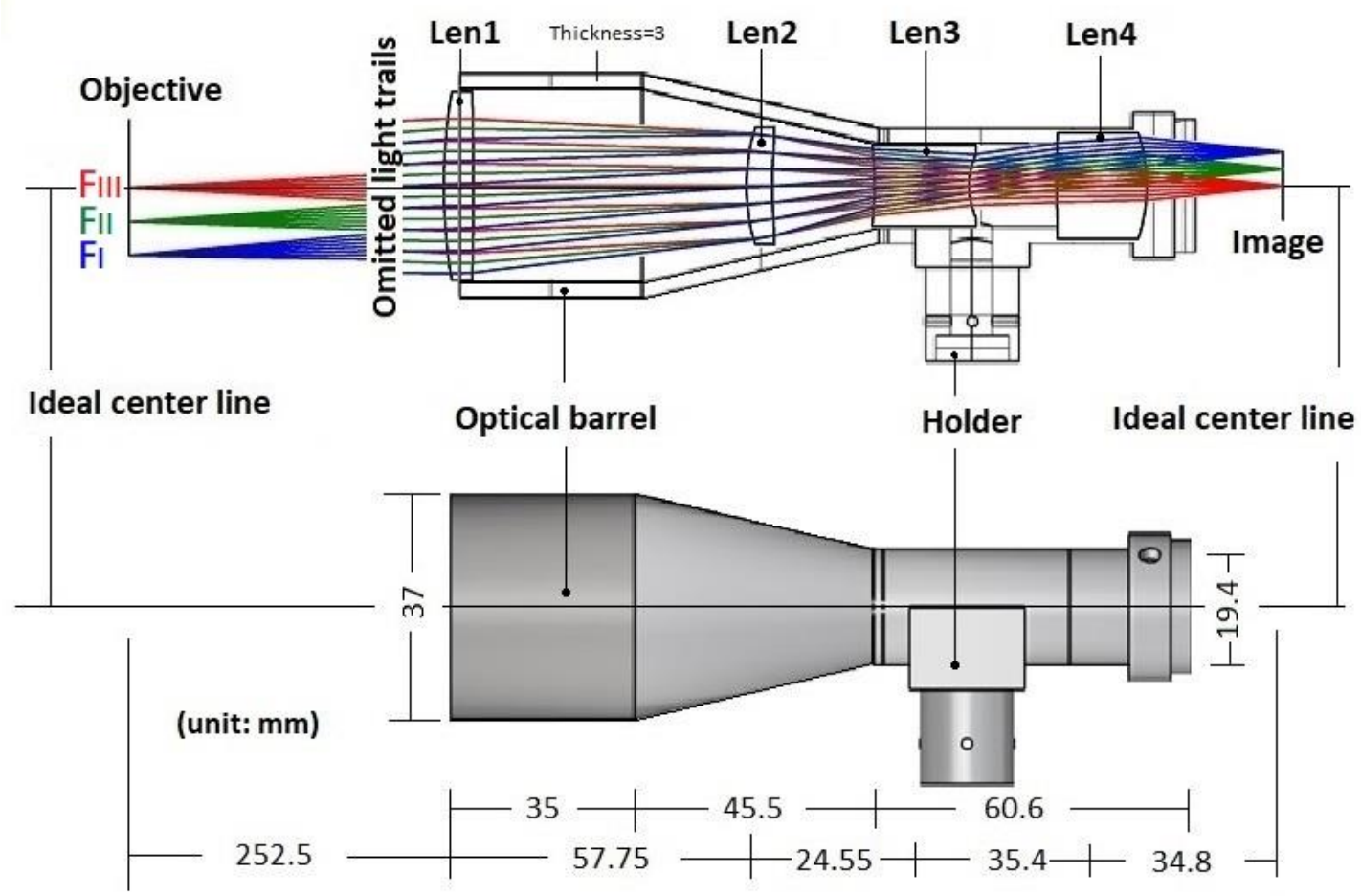

Figure 1. Geometry and optical design of the BTL (unit: $\mathrm{mm}$ ). 


\section{Method and Procedures}

Figure 2 presents a flow chart showing the main steps in the design, optimization, and analysis procedure performed in the present study. Having defined the optical components within the BTL (i.e., the four lenses), CODE V optical software was employed to establish the specification, location, and material of each lens and to determine the required geometrical dimensions of the optical tube. A model of the plastic optical tube was constructed using Rhinoceros software, and Moldex3D simulations were then performed in conjunction with the Taguchi experimental design method to determine the optimal injection molding conditions which minimize the average concentricity error of the optical tube at the planes corresponding to the ideal locations of the four lenses. Finally, the MTF and spot diagram of the BTL were investigated for three different light fields $\left(\mathrm{F}_{\mathrm{I}}, \mathrm{F}_{\mathrm{II}}\right.$, and $\left.\mathrm{F}_{\mathrm{III}}\right)$ entering the objective lens at different distances from the optical axis (see Figure 1). The validity of the optimized design was confirmed by comparing the CODE V results for the modulus transfer function (MTF), spot diagram (SD), and 2D imaging simulation (IMS) of the proposed optical device with those of an ideal BTL device with no coaxiality or concentricity errors and a BLT device molded using the default processing conditions for the selected polymer material.

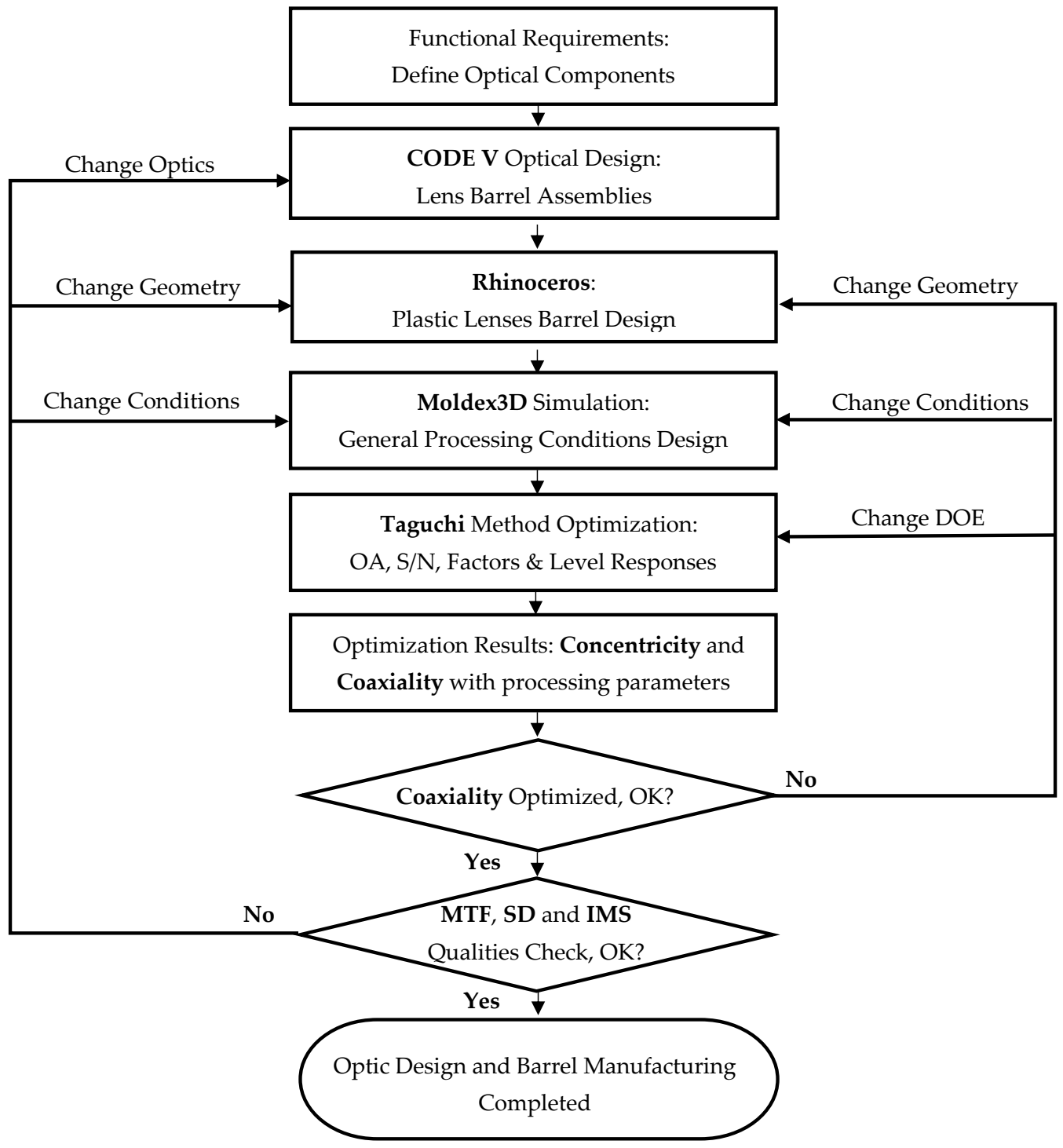

Figure 2. Flow chart showing the main steps in the optical design and injection molding optimization procedure for the BTL. 


\subsection{Materials and Geometry Model}

In performing the analysis, it was assumed that the plastic barrel of the BTL was fabricated of PA66 (Polyamide 66 or Nylon 66) polymer (TECHNYL A 216, Solvay Engineering Plastics), with the material properties and recommended injection molding parameters shown in Table 1. Figure 3a shows the relationship between the viscosity of PA66 and the shear rate at different temperatures. Figure $3 \mathrm{~b}$ shows the $\mathrm{P}-\mathrm{v}-\mathrm{T}$ (pressure/specific volume/temperature) properties of the PA66 material as a function of the shear rate and temperature, and this characteristic was used to calculate the degree of compression of the PA66 material in the packing stage. Table 2 shows the material, geometry dimensions, and optical properties of the four lenses within the BTL.

Table 1. Material properties and recommended processing conditions for PA66 (TECHNYL A 216, Solvay Engineering Plastics).

\begin{tabular}{lcc}
\hline Material Properties & Values & Unit \\
\hline Density & 1140 & $\mathrm{Kg} / \mathrm{m}^{3}$ \\
Specific heat & $2 \times 10^{-11}$ & $\mathrm{~J} / \mathrm{Kg} .{ }^{\circ} \mathrm{C}$ \\
Heat conduction coefficient & 0.25 & $\mathrm{~J} / \mathrm{s} . \mathrm{m} .{ }^{\circ} \mathrm{C}$ \\
Mold shrinkage & 1.90 & ${ }^{\circ}$ \\
Tensile modulus & 3000 & $\mathrm{MPa}$ \\
Melt temperature & 263 & ${ }^{\circ} \mathrm{C}$ \\
Coefficient of linear thermal expansion $\left(23-85^{\circ} \mathrm{C}\right)$ & $7 \times 10^{-5}$ & ${ }^{\circ} \mathrm{C}$ \\
Viscosity vs. shear rate under different temperatures & shown in Figure $3 \mathrm{a}$ \\
P-v-T & shown in Figure $3 \mathrm{~b}$ \\
\hline Processing Conditions in Injection Molding (Recommended) & Values & $\mathrm{Unit}$ \\
\hline Maximum injection pressure & $180-240$ & $\mathrm{MPa}$ \\
Maximum packaging pressure & $180-240$ & $\mathrm{MPa}$ \\
Melt temperature & $270-290$ & ${ }^{\circ} \mathrm{C}$ \\
Mold temperature & $60-100$ & ${ }^{\circ} \mathrm{C}$ \\
Cooling time & $11-17$ & $\mathrm{~s}$ \\
Ejection temperature & 190 & ${ }^{\circ} \mathrm{C}$ \\
Curing temperature & 210 & ${ }^{\circ} \mathrm{C}$ \\
\hline
\end{tabular}

Table 2. Optical properties and geometrical dimensions of lenses in the BTL.

\begin{tabular}{|c|c|c|c|c|c|c|c|}
\hline Lens No. & Glass/SCHOTT & $\begin{array}{c}\text { Curvature } \\
\text { Radius } \\
\text { (mm) }\end{array}$ & $\begin{array}{c}\text { Thickness } \\
\text { (mm) }\end{array}$ & $\begin{array}{c}\text { Refractive } \\
\text { Index } \\
(-)\end{array}$ & $\begin{array}{c}\text { Abbe Value } \\
(-)\end{array}$ & $\begin{array}{c}\text { Partial } \\
\text { Dispersion } \\
(-)\end{array}$ & $\begin{array}{c}\text { Dispersion } \\
\text { (NL-N1) } \\
(-)\end{array}$ \\
\hline \multirow{2}{*}{ Len 1} & \multirow{2}{*}{ NLAK33A } & 109.2083 & \multirow{2}{*}{5.0065} & \multirow{2}{*}{1.75393} & \multirow{2}{*}{52.271} & \multirow{2}{*}{0.30323} & \multirow{2}{*}{0.01442} \\
\hline & & -786.0770 & & & & & \\
\hline \multirow{2}{*}{ Len 2} & \multirow{2}{*}{ NLAK33B } & 38.8283 & \multirow{2}{*}{5.0044} & \multirow{2}{*}{1.75500} & \multirow{2}{*}{52.300} & \multirow{2}{*}{0.30321} & \multirow{2}{*}{0.01444} \\
\hline & & 137.9732 & & & & & \\
\hline \multirow{2}{*}{ Len 3} & \multirow{2}{*}{ FK5HTI } & -67.9914 & \multirow{2}{*}{18.1944} & \multirow{2}{*}{1.48748} & \multirow{2}{*}{70.470} & \multirow{2}{*}{0.30977} & \multirow{2}{*}{0.00692} \\
\hline & & 15.3674 & & & & & \\
\hline \multirow{2}{*}{ Len 4} & \multirow{2}{*}{ LAFN7 } & 427.9534 & \multirow{2}{*}{17.2165} & \multirow{2}{*}{1.74950} & \multirow{2}{*}{34.951} & \multirow{2}{*}{0.29414} & \multirow{2}{*}{0.02144} \\
\hline & & -33.0637 & & & & & \\
\hline
\end{tabular}



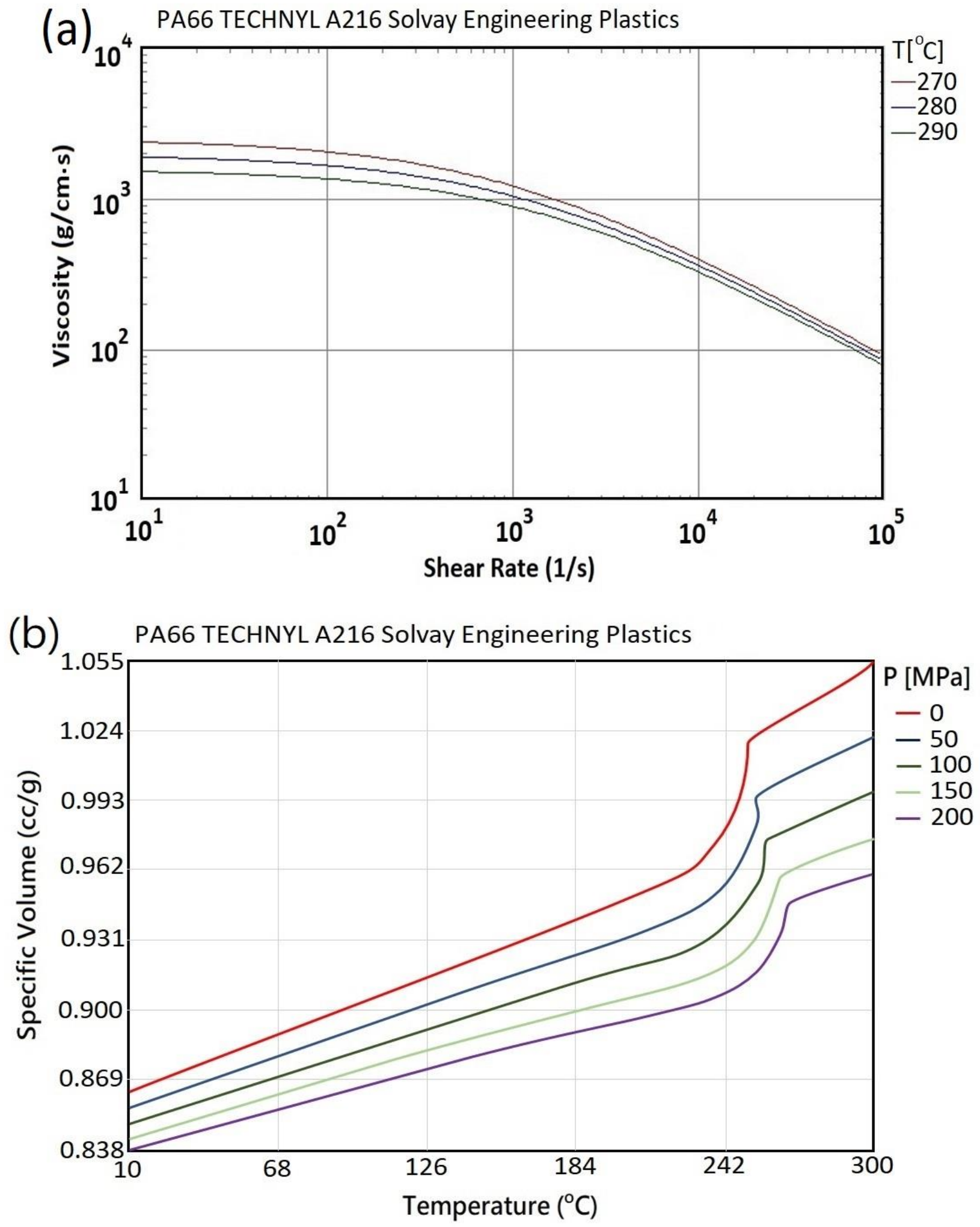

Figure 3. (a) Viscosity and (b) P-v-T properties of PA66 material (source: Moldex3D material library). 


\subsection{Mold Flow Analysis and Taguchi Experimental Method}

A geometric model of the BTL barrel was constructed in Rhinoceros and exported to Moldex3D-Mesh to define the corresponding molding system (see Figure 4) with the runner system (see Figure 4a) and cooling system (see Figure $4 \mathrm{~b}$ ). Figure 4a shows that the PA66 melt was injected into the mold cavity with four gates through the runner system, and the size of the runners including the diameter and length is shown in the description. The coolant used in the entire injection molding system was water, and the water entered the cooling runner at a temperature of $25{ }^{\circ} \mathrm{C}$ to cool the mold (see Figure $4 \mathrm{~b}$ ). The injection molding process was then simulated using Moldex3D. The simulations considered five molding parameters, namely, the maximum injection pressure, the maximum packing pressure, the melt temperature, the mold temperature, and the cooling time. Each molding parameter (control factor) was assigned four different level settings. Hence, the Taguchi experiments were configured in an $\mathrm{L}_{16}\left(5^{4}\right)$ orthogonal array $(\mathrm{OA})$, as shown in Table 3 (gray region). The aim of the Taguchi experiments (i.e., Moldex3D simulations) was to determine the combination of control factor level settings which minimized the concentricity error of the BTL barrel at the position of each lens and hence optimized the coaxiality of the tube. Hence, for each run of the OA, the quality of the simulation outcome was evaluated using the following smaller-the-better $\mathrm{S} / \mathrm{N}$ (signal-to-noise) ratio:

$$
\mathrm{S} / \mathrm{N}=-10 \log \left(\frac{1}{n} \sum_{i=1}^{n} y_{i}^{2}\right),
$$

where $y_{i}$ is the concentricity of the barrel at the measurement plane $i(i=1 \sim 4)$, and $n$ is the number of measured points in the trial.

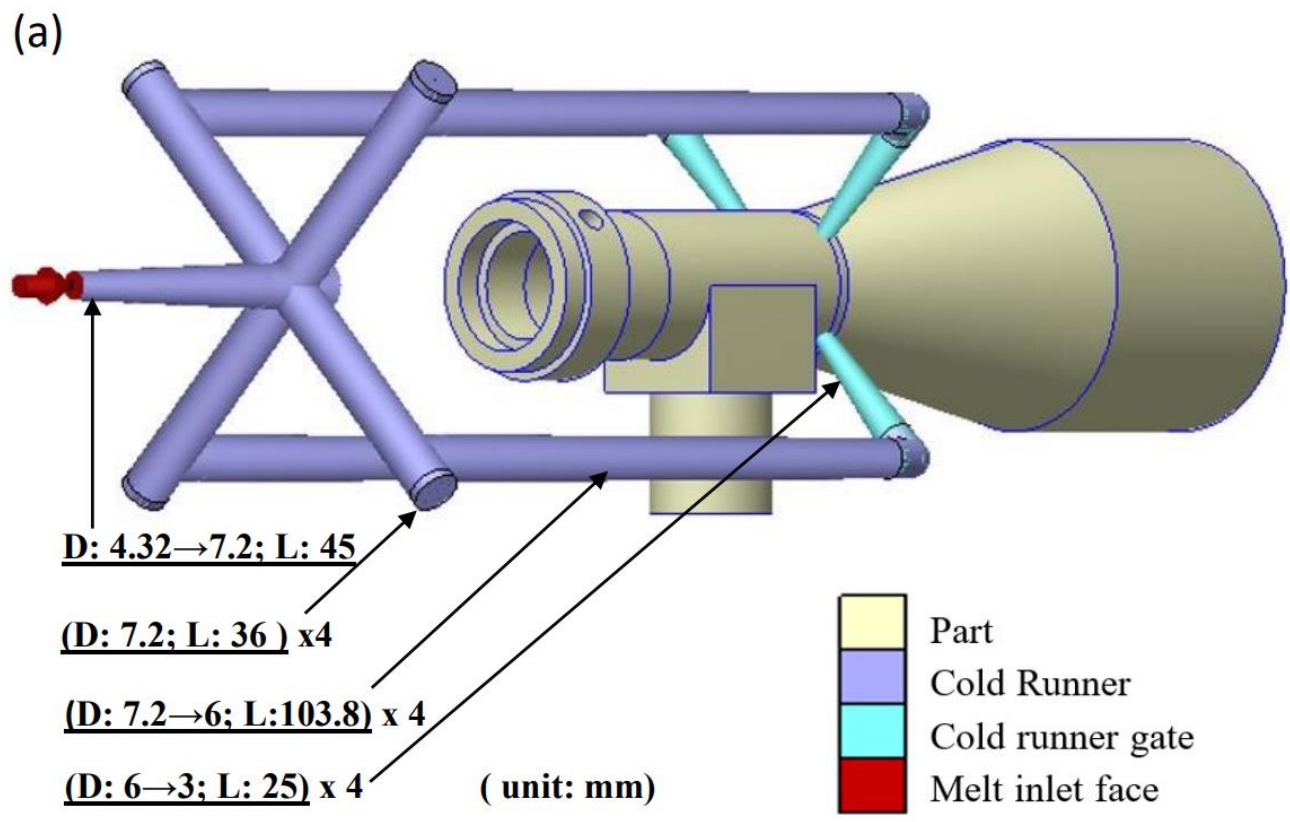

Figure 4. Cont. 
(b)
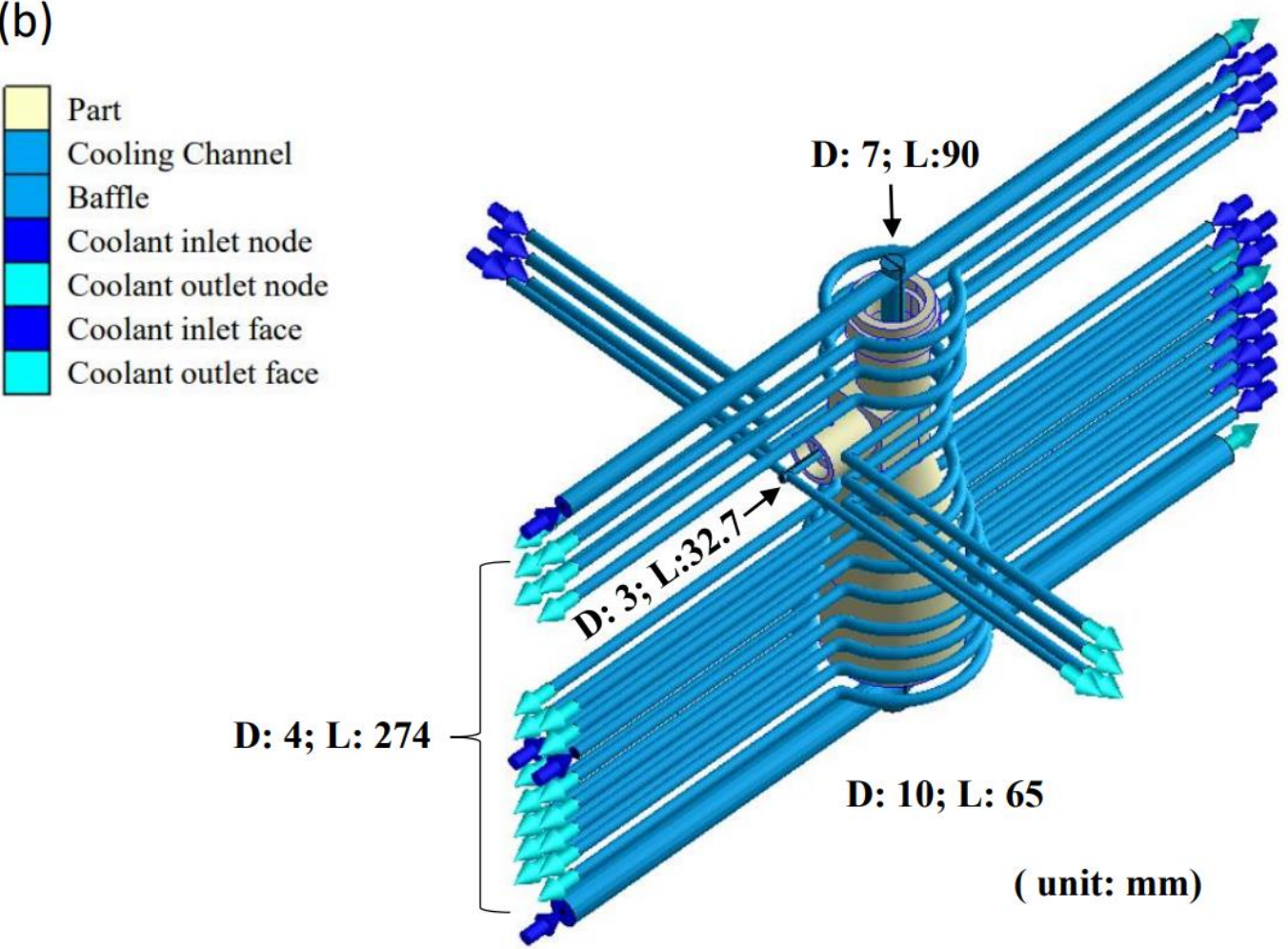

Figure 4. (a) Injection molding system and (b) cooling system of the BTL (D: diameter; L: length; unit: $\mathrm{mm}$ ).

Table 3. Taguchi $\mathrm{L}_{16}\left(5^{4}\right)$ orthogonal array for coaxiality optimization of the BTL.

\begin{tabular}{|c|c|c|c|c|c|}
\hline \multirow[b]{2}{*}{ Trials } & \multicolumn{5}{|c|}{ Processing Factors } \\
\hline & $\begin{array}{c}\text { A } \\
\text { Maximum } \\
\text { Injection } \\
\text { Pressure } \\
\text { (MPa) }\end{array}$ & $\begin{array}{c}\text { B } \\
\text { Maximum } \\
\text { Packing } \\
\text { Pressure } \\
\text { (MPa) }\end{array}$ & $\begin{array}{c}\text { C } \\
\text { Melt } \\
\text { Temperature }\left({ }^{\circ} \mathrm{C}\right)\end{array}$ & $\begin{array}{c}\text { D } \\
\text { Mold } \\
\text { Temperature } \\
\left({ }^{\circ} \mathrm{C}\right)\end{array}$ & $\begin{array}{c}\text { E } \\
\text { Cooling } \\
\text { Time } \\
\text { (s) }\end{array}$ \\
\hline General Parameters & 200 & 200 & 280 & 80 & 13 \\
\hline 1 & 180 & 180 & 275 & 70 & 11 \\
\hline 2 & 180 & 200 & 280 & 80 & 13 \\
\hline 3 & 180 & 220 & 285 & 90 & 15 \\
\hline 4 & 180 & 240 & 290 & 100 & 17 \\
\hline 5 & 200 & 180 & 280 & 90 & 17 \\
\hline 6 & 200 & 200 & 275 & 100 & 15 \\
\hline 7 & 200 & 220 & 290 & 70 & 13 \\
\hline 8 & 200 & 240 & 285 & 80 & 11 \\
\hline 9 & 220 & 180 & 285 & 100 & 13 \\
\hline 10 & 220 & 200 & 290 & 90 & 11 \\
\hline 11 & 220 & 220 & 275 & 80 & 17 \\
\hline 12 & 220 & 240 & 280 & 70 & 15 \\
\hline 13 & 240 & 180 & 290 & 80 & 15 \\
\hline 14 & 240 & 200 & 285 & 70 & 17 \\
\hline 15 & 240 & 220 & 280 & 100 & 11 \\
\hline 16 & 240 & 240 & 275 & 90 & 13 \\
\hline Optimal Parameters & 220 & 240 & 275 & 90 & 17 \\
\hline
\end{tabular}




\subsection{Roundness, Concentricity, and Coaxiality Measures}

For cylindrical objects such as the BTL barrel considered in the present study, the manufacturing quality can be evaluated by three different metrics: the roundness, the concentricity, and the coaxiality. Traditional methods for evaluating the roundness of manufactured parts include the least squares circle (LSC) method, the minimum zone tolerance circle (MZC) method, the maximum inscribed circle (MIC) method, and the minimum circumscribed circle (MCC) method [19]. In the present study, the roundness of the BTL barrels produced using the different processing conditions specified in the Taguchi OA was evaluated using the LSC method [20]. In particular, a fitting process was applied to determine the circle which produced the minimum sum of the square error $F(x, y)$ with the actual circular profile of the tube, i.e.,

$$
F(x, y)=\sum_{i=1}^{n}\left[r(x, y)^{2}-R_{c}{ }^{2}\right]^{2}=\sum_{i=1}^{n}\left[\left(x-x_{c}\right)^{2}+\left(y-y_{c}\right)^{2}-R_{c}{ }^{2}\right]^{2}
$$

where $r(x, y)$ is the distance between the measured point $(x, y)$ and the unknown center $\left(x_{c}, y_{c}\right)$ of the circle, $n$ is the number of measured points, and $R_{c}$ is the radius of the least squares circle. Taking the center $\left(x_{c}, y_{c}\right)$ of the least squares error (LSE) circle as the center of the circle after processing deformation, the LSE circle center was calculated at each of the four reference planes (i.e., lens positions) in the BTL barrel. The concentricity, $d$, of the barrel at each plane was then computed as the offset of the LSE circle center from the designed datum value $\left(x_{0}, y_{0}\right)=(0,0)$. Finally, the concentricity values obtained at the four reference planes were averaged to evaluate the coaxiality of the tube [21-23]. For convenience, the corresponding mathematical derivations are given in the following.

The concentricity of the BTL at plane $i$ was evaluated as

$$
d_{i}=\sqrt{\left(x_{c}-x_{o}\right)^{2}+\left(y_{c}-y_{0}\right)^{2}}
$$

The coaxiality (overall concentricity) of the BTL was computed as

$$
\text { Coaxiality }=\sum_{i=1}^{n}\left[d_{i}\right]^{2} / n
$$

\subsection{CODE V Optical Evaluation Using Eccentric Coordinates $\left(x_{c}, y_{c}, z_{c}\right)$}

Following the Taguchi/Moldex3D simulations, the concentricity coordinates $\left(x_{c}, y_{c}\right)$ and axial displacements $\left(z_{c}\right)$ of each lens in the barrel were input to CODE V software in order to evaluate the optical performance of the device. The performance was evaluated in terms of three metrics, namely, the MTF, the spot diagram, and the 2D imaging simulation. In general, the MTF indicates how a lens reproduces contrast over a broad range of spatial frequencies, while the spot diagram computes the focused image size and provides a quick and qualitative assessment of the overall quality of the lens assembly. Finally, the 2D imaging simulation (resolution results with grayscale analysis) provides a further simple visualization of the optical system performance [24].

\section{Results and Discussion}

\subsection{Taguchi Optimization Results}

The general (or standard for specific machines) processing parameters for the considered PA66 polymer material were taken from the manufacturer's specification as follows: maximum injection pressure $200 \mathrm{MPa}$, maximum packing pressure $200 \mathrm{MPa}$, melt temperature $280^{\circ} \mathrm{C}$, mold temperature $80^{\circ} \mathrm{C}$, and cooling time $13 \mathrm{~s}$ (see the upper row in Table 3 ). However, the Taguchi analysis results indicated that the optimal parameter settings (i.e., the parameter settings which minimized the coaxiality error of the BTL tube) were a maximum injection pressure of $220 \mathrm{MPa}$, a maximum packing pressure of $240 \mathrm{MPa}$, a melt temperature of $275^{\circ} \mathrm{C}$, a mold temperature of $90^{\circ} \mathrm{C}$, and a cooling time of $17 \mathrm{~s}$ (see the 
lower row in Table 3). Table 4 shows the Taguchi $\mathrm{S} / \mathrm{N}$ response data for the five control factors and their level settings. As shown, the control factors can be ranked in terms of a diminishing effect on the coaxiality of the tube as follows: maximum packing pressure $>$ melt temperature $>$ cooling time $>$ maximum injection pressure $>$ mold temperature. In other words, the coaxiality of the molded tube is dominated by the packing pressure and melt temperature, while the cooling time, injection pressure, and mold temperature all have more minor effects. Table 4 shows that the $\mathrm{S} / \mathrm{N}$ ranges of factor $\mathrm{A}$ (maximum injection pressure) and factor $\mathrm{D}$ (molding temperature) are much smaller than those of factor B (maximum packing pressure), factor C (melt temperature), and factor $\mathrm{E}$ (cooling time). It is worth noting that under the condition of coaxial optimization of control factors $A$ and $D$, their individual influence is significantly smaller than that of other factors $(B, C$, and $\mathrm{E}$ ). However, factor $\mathrm{A}$ and factor $\mathrm{D}$ are different in the $\mathrm{S} / \mathrm{N}$ range (but their values are very close). Therefore, their impact evaluation should be discussed in consideration of other different processing conditions.

Table 4. Signal-to-noise (S/N) response of control factors and level settings.

\begin{tabular}{cccccc}
\hline \multirow{2}{*}{$\begin{array}{l}\text { Level/ Factor } \\
\text { Range/Rank }\end{array}$} & A & B & C & D & E \\
\cline { 3 - 6 } & 18.42426 & 17.93074 & 18.64934 & 18.4332 & 18.38978 \\
Level 1 (dB) & 18.44004 & 18.29598 & 18.51562 & 18.45852 & 18.36406 \\
Level 2 (dB) & 18.4714 & 18.63066 & 18.3822 & 18.45247 & 18.44444 \\
Level 3 (dB) & 18.4491 & 18.92741 & 18.23765 & 18.44061 & 18.58652 \\
Level 4 (dB) & 0.047142 & 0.996663 & 0.41169 & 0.025322 & 0.22246 \\
S/N Range (dB) & 4 & 1 & 2 & 5 & 3 \\
Influence Rank & 4 & & & & \\
\hline
\end{tabular}

In general, the results show that a larger maximum packing pressure, a lower melt temperature, and a longer cooling time are beneficial in reducing the concentricity error (in each plane) of the tube and improving the coaxiality as a result. Table 5 shows the injection molding simulation parameters for the general design and the optimal design to verify the results of the Taguchi method.

Figure 5 shows the real sprue pressure changes and real flow rate changes in the filling stage and the packing stage after the injection molding simulation. It can be seen that increasing the maximum packing pressure and the maximum injection pressure helps to maintain the stability of the flow rate (about $31.97 \mathrm{~cm}^{3} / \mathrm{s}$ ) and is very close to the expected constant flow rate $\left(34.05 \mathrm{~cm}^{3} / \mathrm{s}\right)$. For the $\mathrm{V} / \mathrm{P}$ (velocity-to-pressure) transition point, the general design and optimal design have values of $2.098 \mathrm{~s}$ and $2.097 \mathrm{~s}$, respectively. The setting of the maximum injection pressure helps to keep the flow rate at a certain level during the filling stage and limits the injection pressure during the filling stage to prevent mold or machine failure. In fact, the real injection pressure also changes at the set desired flow rate, and the real injection pressure is always less than the maximum injection pressure during the filling stage. On the other hand, an injection molding machine with such a high maximum packing pressure setting $(200 \mathrm{MPa})$ is an extreme upper limit and is not widely used throughout the process. Because this paper is a numerical simulation analysis, the setting of the packing pressure does not fully consider the actual situation. Generally speaking, when the packing pressure is too high, the pressure in the mold will be too large. Such a processing procedure can cause stress concentration and residual stress, which can lead to difficulty in ejection and even cracking. For the peak flow rate shown in Figure 5, this is not a typical velocity profile for injection molding. The possible reason is that the numerical simulation in this study adopted a one-stage flow rate setting. Under the influence of all the complex processing factors, the cavity space that is not fully filled must be filled before the expected end of time. Therefore, there is a tendency for the flow rate to suddenly increase before entering the packing stage. Of course, this situation still needs further confirmation and discussion. 
Table 5. Injection molding process parameters for general design and optimal design.

\begin{tabular}{|c|c|c|}
\hline & General Design & Optimal Design \\
\hline \multicolumn{3}{|l|}{ Filling } \\
\hline Filling time (s) & 2.13 & 2.13 \\
\hline Melt temperature $\left({ }^{\circ} \mathrm{C}\right)$ & 280 & 275 \\
\hline Mold temperature $\left({ }^{\circ} \mathrm{C}\right)$ & 80 & 90 \\
\hline Maximum injection pressure ( $\mathrm{MPa})$ & 200 & 220 \\
\hline Injection volume $\left(\mathrm{cm}^{3}\right)$ & 68.1 & 68.1 \\
\hline \multicolumn{3}{|l|}{ Packing } \\
\hline Packing time (s) & 7 & 7 \\
\hline Maximum packing pressure (MPa) & 200 & 240 \\
\hline \multicolumn{3}{|l|}{ Cooling } \\
\hline Cooling time (s) & 13 & 17 \\
\hline Mold-open time (s) & 5 & 5 \\
\hline Eject temperature $\left({ }^{\circ} \mathrm{C}\right)$ & 190 & 190 \\
\hline Air temperature $\left({ }^{\circ} \mathrm{C}\right)$ & 25 & 25 \\
\hline \multicolumn{3}{|l|}{ Miscellaneous } \\
\hline Cycle time (s) & 27.13 & 27.13 \\
\hline
\end{tabular}

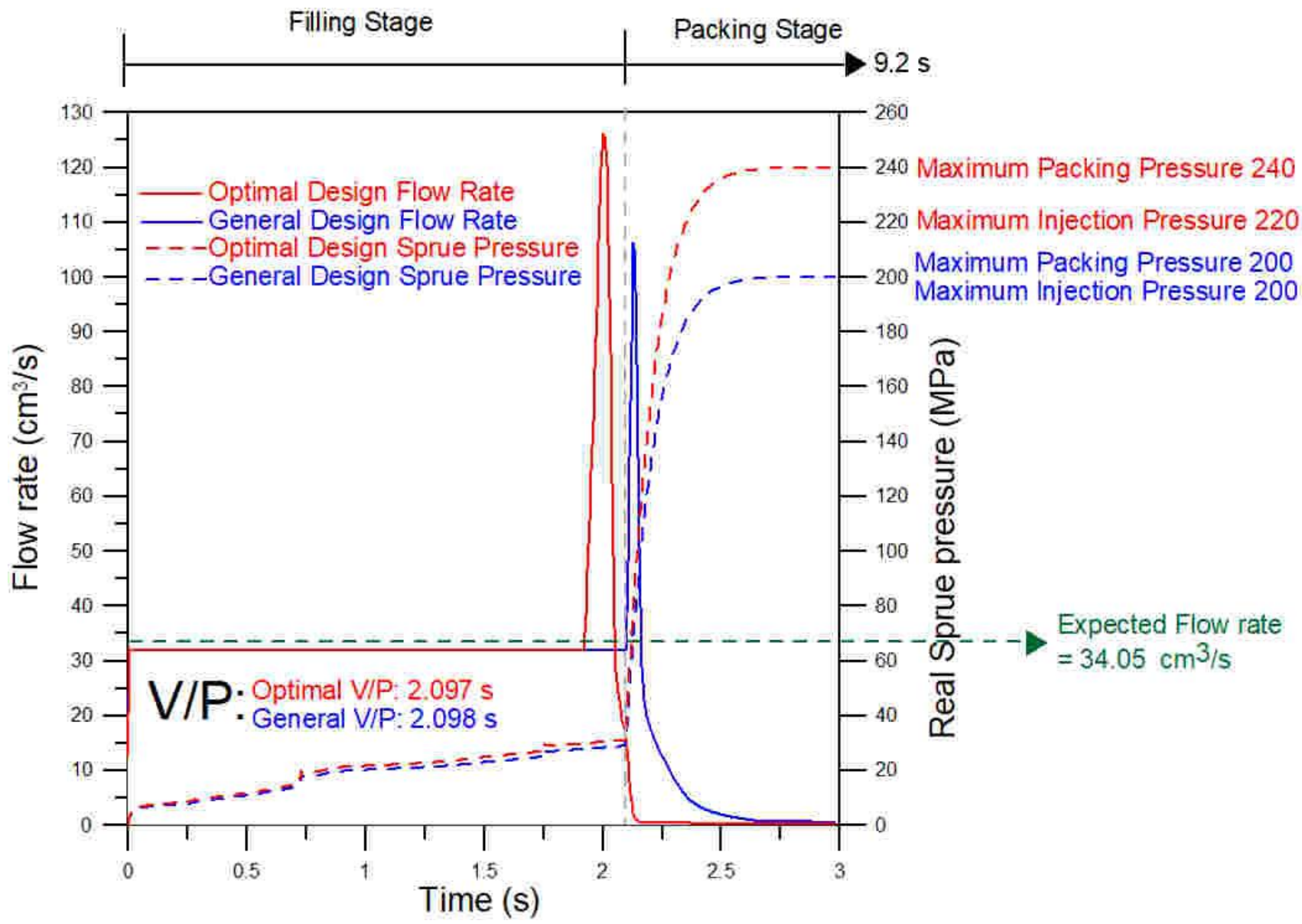

Figure 5. Considering the processing factors (maximum injection pressure and maximum packing pressure), the real sprue pressure change and flow rate change presented by the general design and the optimal design during the filling stage and the packing stage are shown. 
Figure 6 plots the coaxiality error and $\mathrm{S} / \mathrm{N}$ values for each of the 16 runs in the $\mathrm{L}_{16}\left(5^{4}\right)$ $\mathrm{OA}$, together with those for the general (i.e., recommended) processing parameters and optimal processing parameters. As shown, the tube produced using the optimal molding parameters has the maximum $\mathrm{S} / \mathrm{N}$ value of $19.33078 \mathrm{~dB}$ and the minimum coaxiality error of $0.011666 \mathrm{~mm}^{2}$. The $\mathrm{S} / \mathrm{N}$ value and coaxiality error of the optimal tube are $5.76 \%$ higher and $21.5 \%$ lower, respectively, than those of the tube produced using the recommended processing parameters. In other words, the effectiveness of the optimized parameter settings in improving the coaxiality of the BTL tube is confirmed.

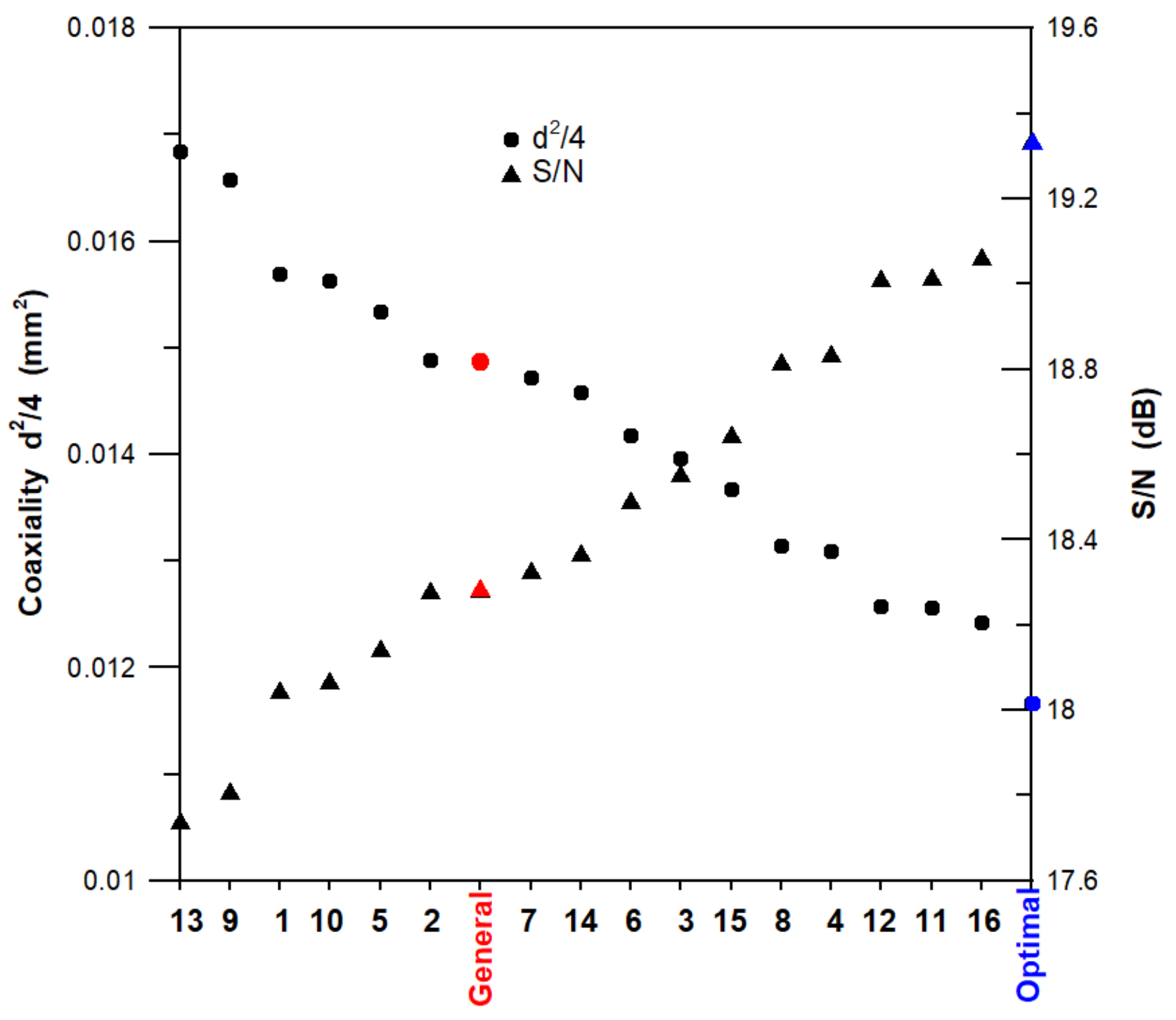

Taguchi Trial Number

Figure 6. Coaxiality and S/N values for different control factor level settings in Moldex3D simulations. 


\subsection{Geometry Analysis}

Table 6 and Figure 7 show the center coordinate positions and concentricity values at the four reference planes $\left(Z_{1} \sim Z_{4}\right)$ of the ideal BTL design (with zero concentricity and coaxiality errors), and the BTL tubes produced using the general and optimal processing conditions. The results indicate that the geometric distortion produced by the manufacturing process is far less than that produced by the asymmetric design of the barrel itself (i.e., the protruding handle structure (see Figure 1)). In addition, the optimal process parameters have a greater effect in reducing the concentricity error at measurement planes $Z_{1}$ and $Z_{4}$ (at the two ends of the BTL barrel) than at planes $Z_{2}$ and $Z_{3}$ (in the central region of the barrel). Notably, however, the results presented in Figure 7 show that even though the concentricity values at the four planes are not markedly improved in the optimal design, the overall coaxiality of the tube is significantly improved compared to that of the tube produced using the general parameters (i.e., from 0.014866 to $0.011666 \mathrm{~mm}$, as shown in Table 6). It should be noted that the runner design and cooling system in this study are based on virtual simulation. If the injection molding process is to be carried out realistically, the interference problem caused by the mold assembly must be considered.

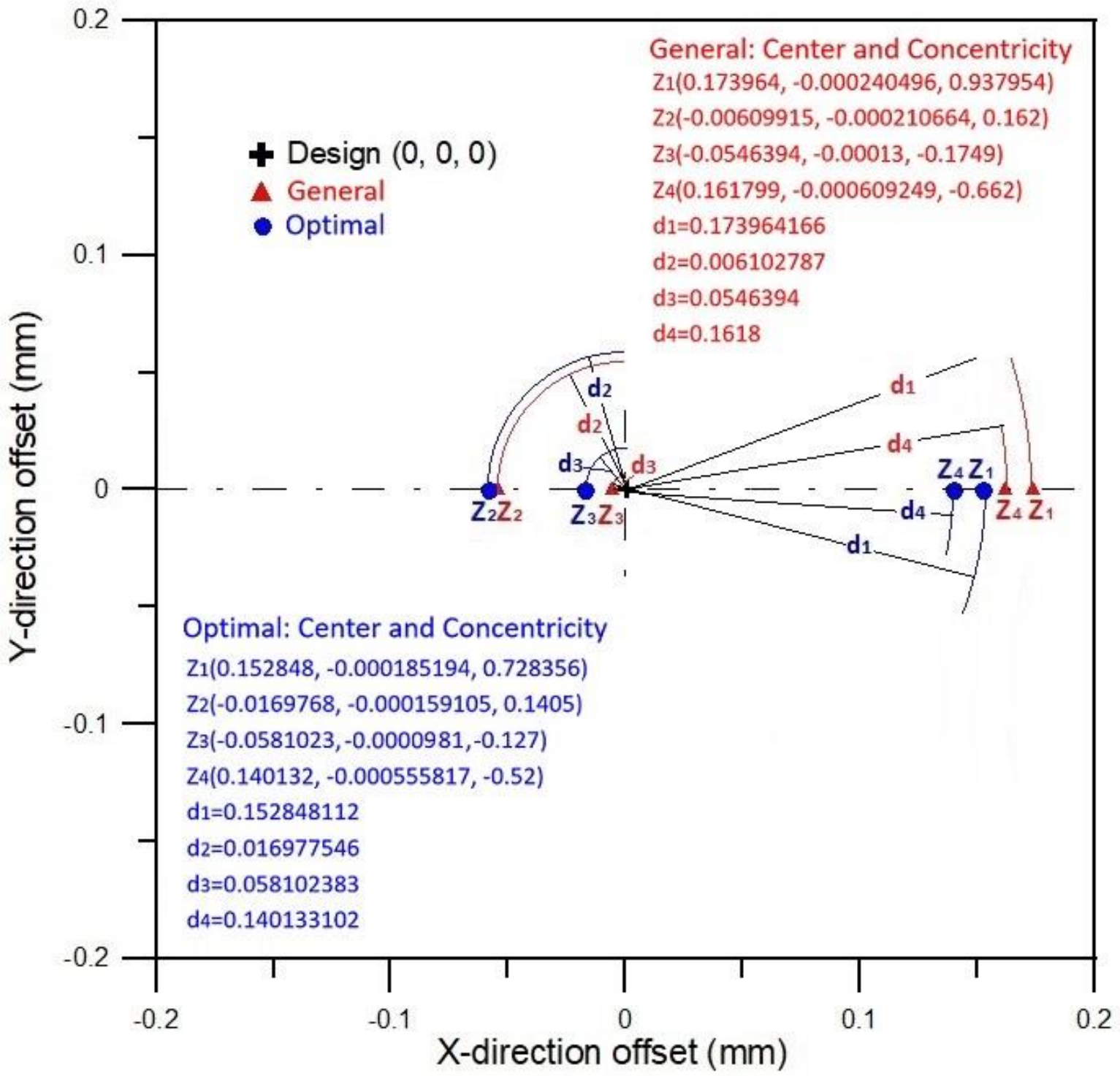

Figure 7. Center distribution and concentricity values in the design, general, and optimal BTL models. 
Table 6. Center coordinates/concentricity values of four reference planes and coaxiality of the optical tube in the design, general, and optimal BTL models.

\begin{tabular}{|c|c|c|c|}
\hline Unit: mm & Design & General & Optimal \\
\hline Planes & \multicolumn{3}{|c|}{$\begin{array}{c}\text { Center Coordinate Bias : } \mathrm{Z}_{i}\left(\Delta \mathrm{Xc}, \Delta \mathrm{Yc}_{\mathrm{c}} \Delta \mathrm{Zc}\right) \\
\text { Concentricity }=d_{i}(i=1-4)(\mathrm{mm}) ; \text { Coaxiality }=\sum_{i=1}^{4}\left(d_{i}\right)^{2} / 4\left(\mathrm{~mm}^{2}\right)\end{array}$} \\
\hline $\mathrm{Z} 1=0$ & $\begin{array}{l}(0,0,0) \\
0\end{array}$ & $\begin{aligned} \mathrm{Z} 1(0.173964,-0.000240496,0.937954) \\
d 1=0.173964166\end{aligned}$ & $\begin{aligned} \mathrm{Z} 1(0.152848, & -0.000185194,0.728356) \\
d 1 & =0.152848112\end{aligned}$ \\
\hline $\mathrm{Z} 2=57.75$ & $\begin{array}{l}(0,0,0) \\
0\end{array}$ & $\begin{array}{l}\mathrm{Z} 2(-0.00609915,-0.000210664,0.162) \\
d 2=0.006102787\end{array}$ & $\begin{array}{c}\mathrm{Z} 2(-0.0169768,-0.000159105,0.1405) \\
d 2=0.016977546\end{array}$ \\
\hline $\mathrm{Z} 3=82.3$ & $\begin{array}{l}(0,0,0) \\
0\end{array}$ & $\begin{array}{c}\mathrm{Z} 3(-0.0546394,-0.00013,-0.1749) \\
d 3=0.0546394\end{array}$ & $\begin{array}{l}\mathrm{Z} 3(-0.0581023,-0.0000981,-0.127) \\
d 3=0.058102383\end{array}$ \\
\hline $\mathrm{Z} 4=117.7$ & $\begin{array}{c}(0,0,0) \\
0\end{array}$ & $\begin{array}{c}\mathrm{Z} 4(0.161799,-0.000609249,-0.662) \\
d 4=0.1618\end{array}$ & $\begin{array}{c}\mathrm{Z} 4(0.140132,-0.000555817,-0.52) \\
d 4=0.140133102\end{array}$ \\
\hline Coaxiality & 0 & 0.014866 & 0.011666 \\
\hline
\end{tabular}

\subsection{Optical Performance}

As described in Section 2.4, the optical performance of the BTL barrel produced using the optimal processing conditions was evaluated by means of MTF plots, spot diagrams, and 2D imaging simulations. For comparison purposes, CODE V simulations were also performed for the ideal design barrel and for the BTL barrel produced using the general processing conditions. Note that the center coordinates and concentricity values of the four lenses in each barrel were assigned the values shown in Table 6.

Figure 8 shows the sagittal and tangential MTF curves of the three BTL tubes (designated as design, general, and optimal) for light fields $F_{I}, F_{I I}$, and $F_{I I I}$ (see Figure 1). In general, an MTF curve closer to the diffraction limit curve indicates a better imaging performance. Consequently, all six MTF curves for the ideal BTL design (with zero concentricity errors) are virtually superimposed on the diffraction limit curve. Moreover, the MTF curves for the optimal tube are closer to the diffraction limit curve than those of the general tube. In other words, the optimized parameters yield a significant improvement in the optical performance of the BTL tube compared to that of the tube produced using the general processing parameters. Figures 9-11 provide a detailed analysis of the imaging performance of the three tubes for light fields I, II, and III. In general, the results confirm that, for all three light fields, the imaging performance of the optimal tube is closer to the ideal performance than that of the general tube. Furthermore, comparing the three figures, it is seen that the imaging performance of the general tube and optimal tube is close to that of the ideal tube for light rays close to the optical axis of the BTL (i.e., $\mathrm{F}_{\mathrm{III}}$ ) but gradually degrades with an increasing distance from the axis (i.e., $\mathrm{F}_{\mathrm{II}}$ and $\mathrm{F}_{\mathrm{I}}$ ). 


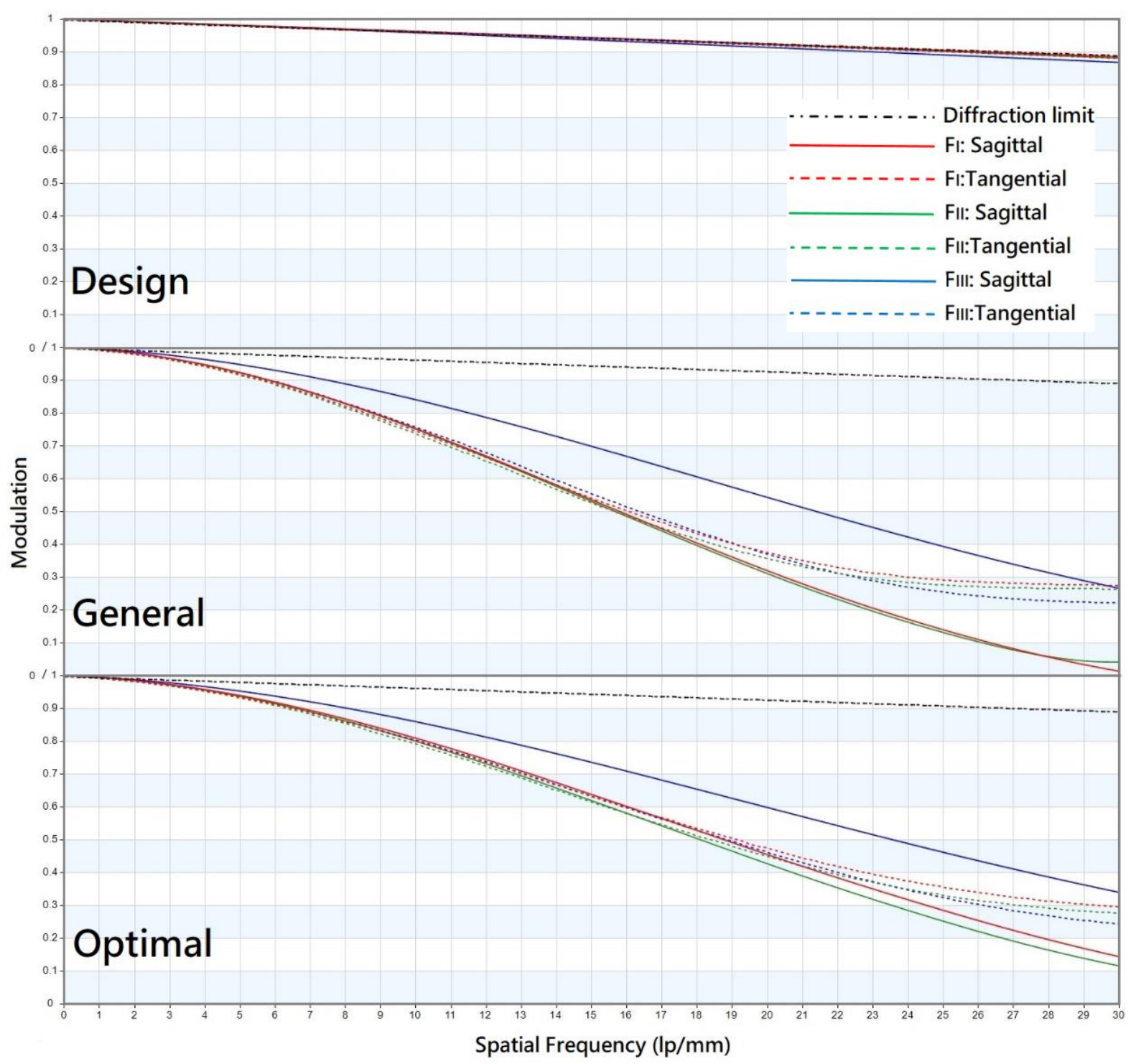

Figure 8. Modulation vs. spatial frequency response for different light fields in the design, general, and optimal BTL models. 


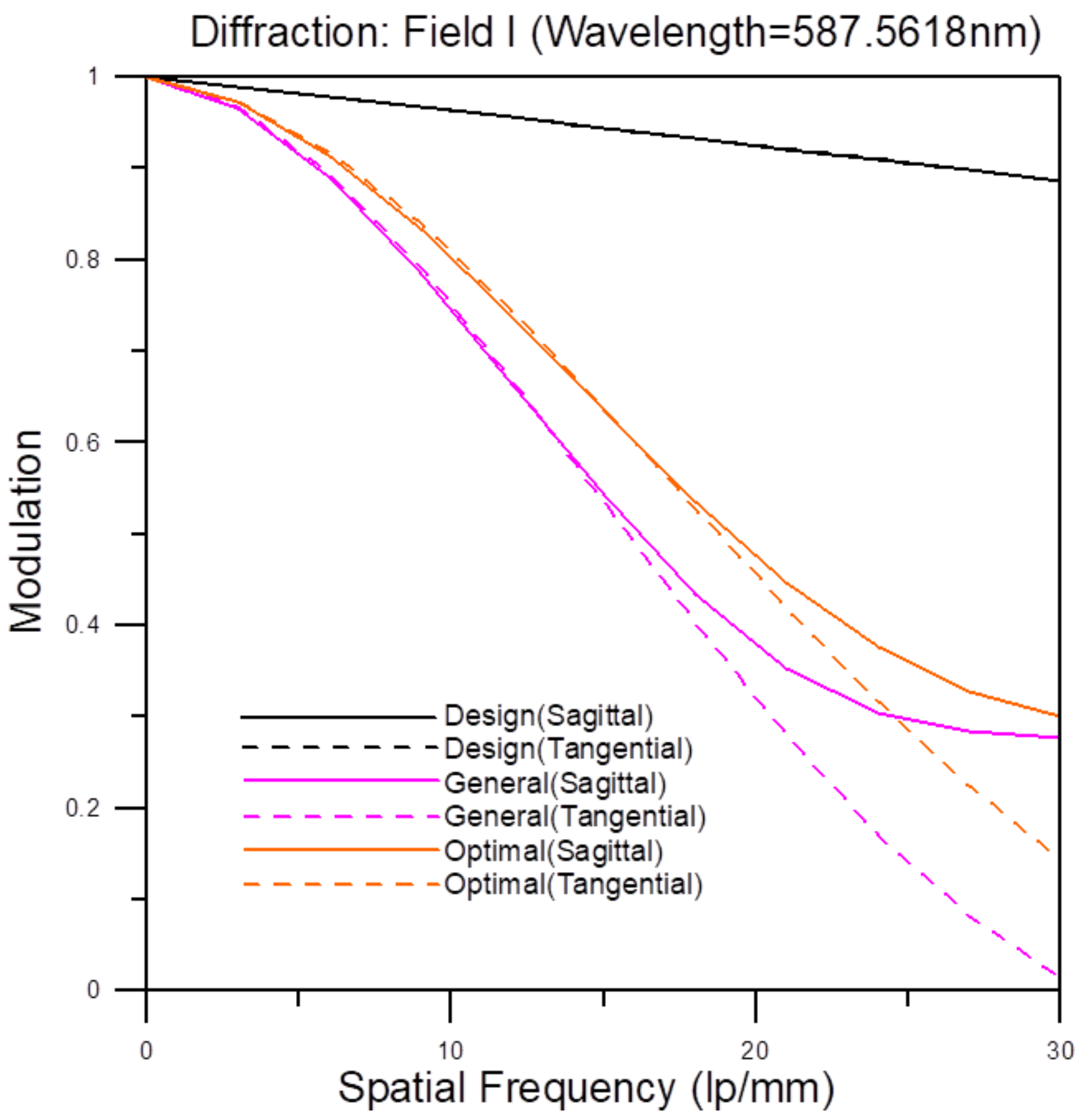

Figure 9. MTF for light field I in the design, general, and optimal BTL models. 


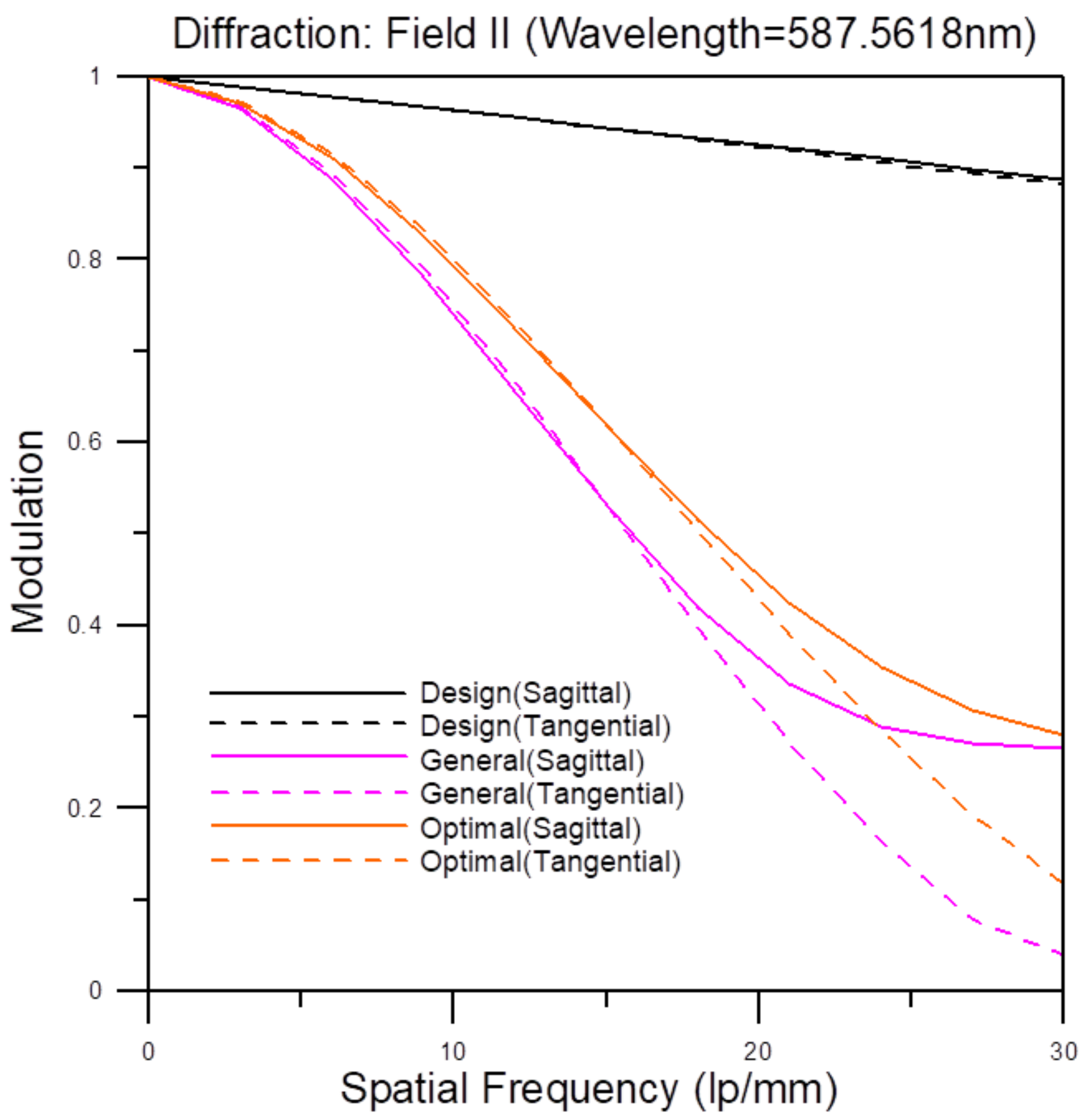

Figure 10. MTF for light field II in the design, general, and optimal BTL models. 


\section{Diffraction: Field III (Wavelength=587.5618nm)}

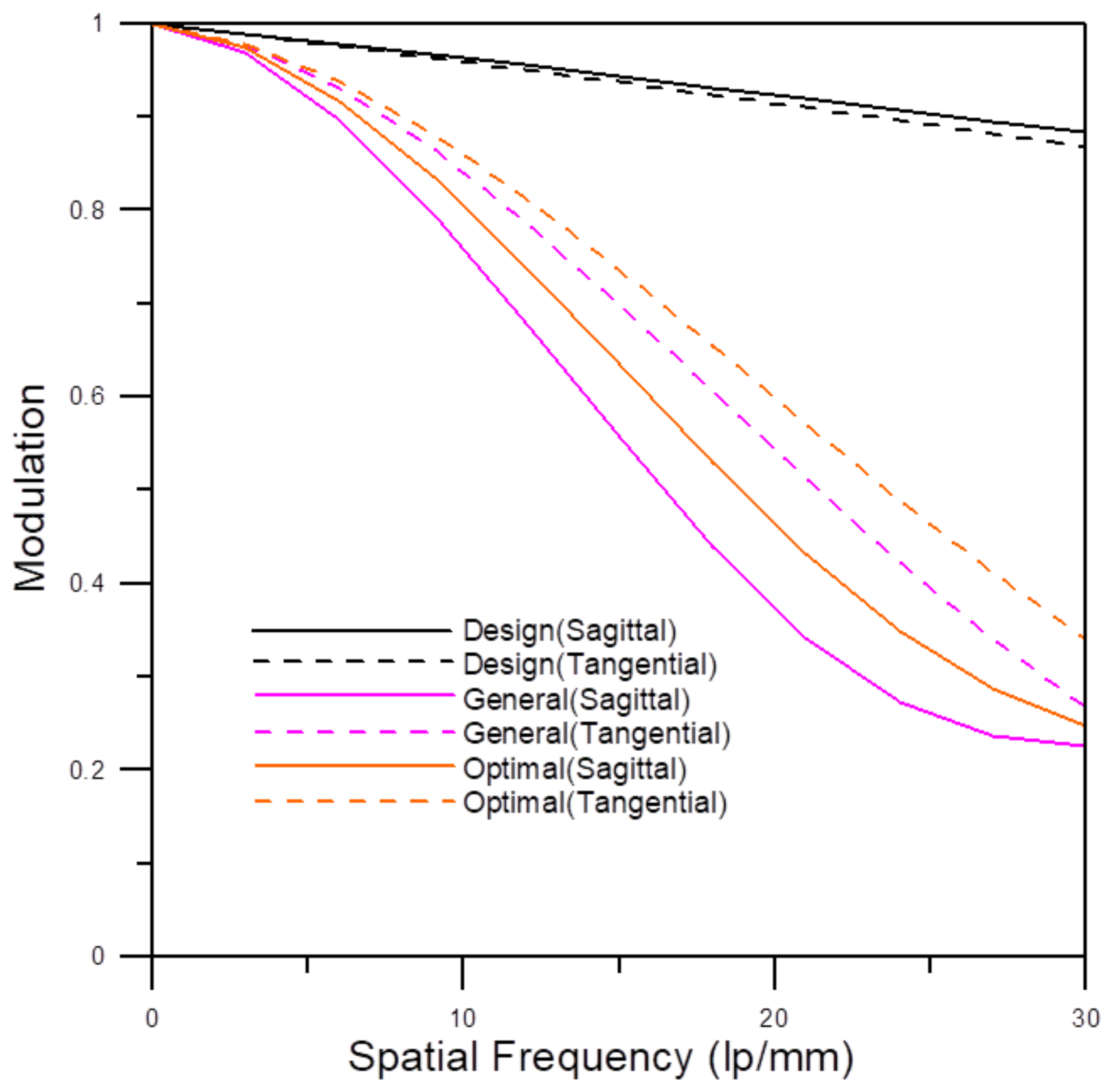

Figure 11. MTF for light field III in the design, general, and optimal BTL models.

Figure 12 shows the spot diagrams of the three light fields on the image plane of the design, general, and optimal BTL tubes. Note that for each spot, the RMS (root mean square) value indicates the root mean square values of all the light spot distribution coordinates, while the $100 \%$ value indicates the smallest circle diameter (in mm) sufficient to encompass all of the individual light spots within the light field. Observing the three sets of light spots for each tube, it is clear that the optimal tube results in a sharper imaging performance than the general tube. Furthermore, examining the spot diagrams for light field $\mathrm{F}_{\mathrm{III}}$ (closest to the optical axis), the minimum circumscribed circle diameters of the design, general, and optimal tubes are found to be $0.002281 \mathrm{~mm}, 0.047270 \mathrm{~mm}$, and $0.040569 \mathrm{~mm}$, respectively. In other words, the optimal tube reduces the focused spot size by $14.2 \%$ compared to that of the general tube. The corresponding improvement values for the $\mathrm{F}_{\mathrm{II}}$ and $\mathrm{F}_{\mathrm{III}}$ fields are $12.8 \%$ and $10.5 \%$, respectively. Similarly, the optimal tube improves the RMS value of the 
focus spot size by $15.4 \%$ compared to that of the general tube for light field $\mathrm{F}_{\mathrm{III}}$, and $13.7 \%$ and $11.1 \%$, respectively, for light fields $\mathrm{F}_{\mathrm{II}}$ and $\mathrm{F}_{\mathrm{I}}$. In other words, the spot diagram results confirm that the optimal tube, with an improved coaxiality, produces a better overall optical quality than the general tube.

Design General Optimal

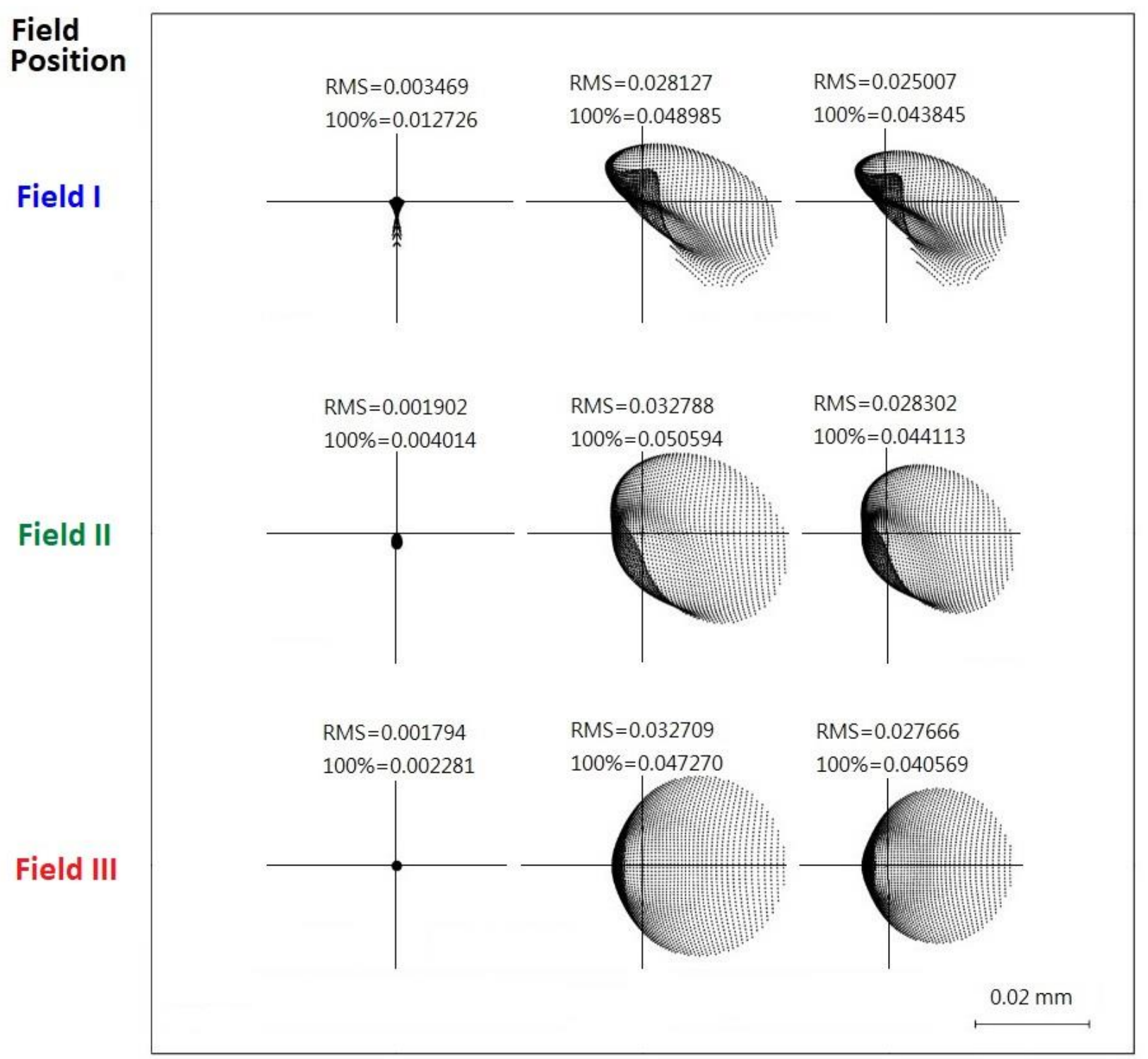

Figure 12. Spot diagrams of three light fields in the design, general, and optimal BTL models.

\subsection{Imaging Simulation: Grayscale Analysis of Imaging Quality}

The imaging quality of the optimal BTL device was further evaluated by means of grayscale analyses. Figure 13 shows the 1951 USAF resolution test chart commonly used to evaluate the optical imaging quality of lens combinations [25]. Note that the dotted circles correspond to different fields of view (FOVs) with a gradually increasing scale from 0 (blue circle) to 1 (black circle). Figure 14 presents a qualitative comparison of the imaging performance of the ideal (design), general, and optimal BTL designs for the right-hand region of the resolution test chart and numeral " 2 " in the top-left corner of the chart. Although a slight improvement in the imaging quality is observed for the optimal design, it is unconvincing. Accordingly, quantitative grayscale analysis simulations were conducted 
along the yellow reference line indicated in the four images in Figure 14 and shown on the right-hand side of Figure 13. As shown in Figure 15a, the analysis was conducted over a distance of 340 pixels, extending from pixel 140 (prior to the first block of three vertical lines in the resolution test chart) to pixel 480 (after the final block of three vertical lines in the test chart). Figure $15 \mathrm{~b}$ shows the variation in the grayscale intensity along the considered line as observed through the ideal BTL, general BTL, and optimal BTL. In Figure 15b, there are 18 peak groups corresponding to the black and white contrast area of the 18 areas crossed by the yellow line in Figure 15a. The black and white interface is grayscaled due to optical errors and imaging characteristics. These differences can be used to explain the pros and cons of imaging. To better evaluate and compare the imaging qualities of the three BTL designs, the grayscale profiles shown in Figure 15 were partitioned into three sub-profiles corresponding to the 1st peak group, 8th peak group, and 18th peak group in Figure 15. The corresponding results are presented in Figure $16 a-c$, respectively, where a grayscale curve closer to the objective curve indicates an improved imaging quality (i.e., a lower imaging distortion).

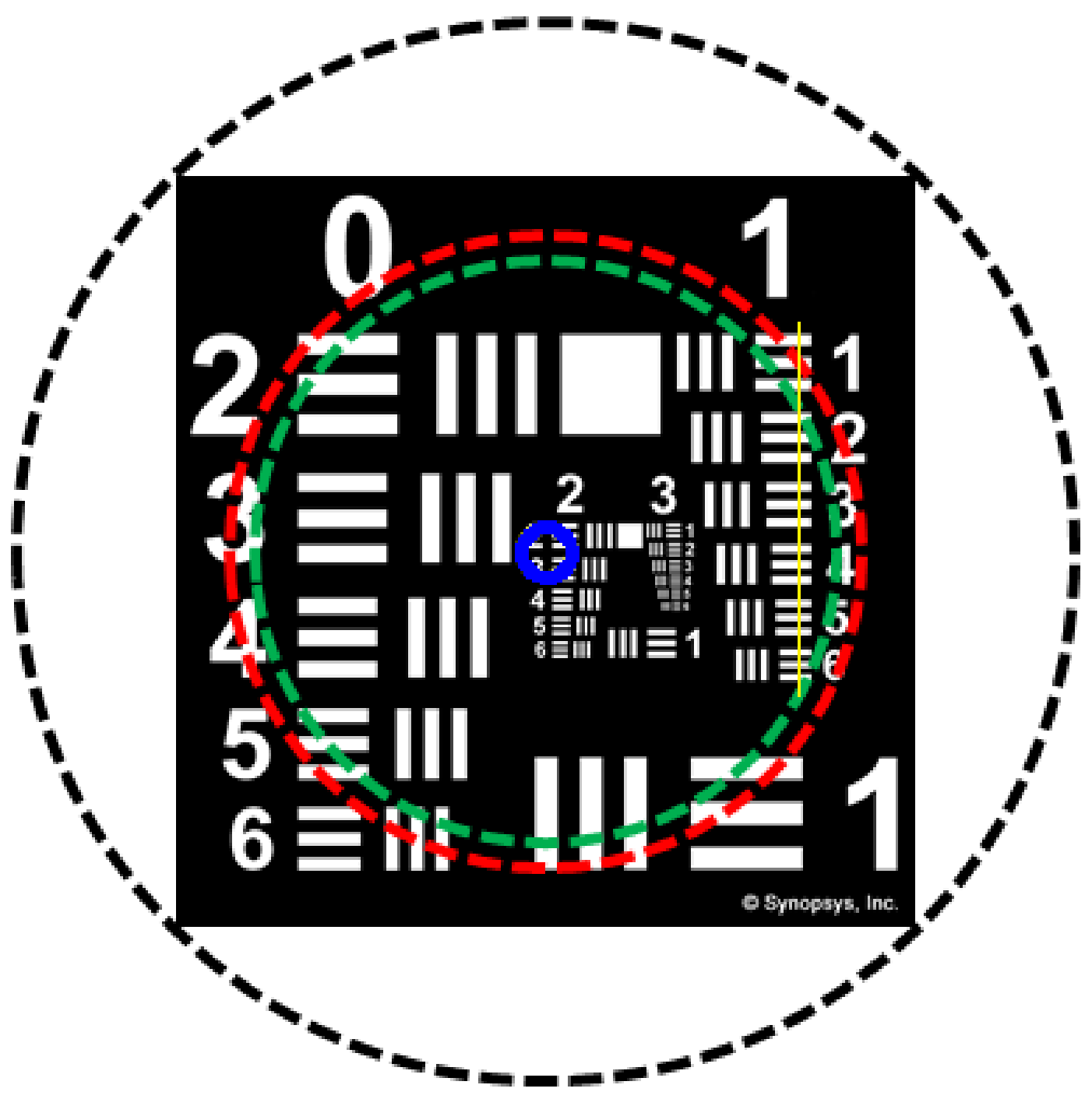

Figure 13. 1951 USAF resolution test chart with graduated FOV. Black circle: FOV = 1; red circle: FOV $=0.6$; green circle: $\mathrm{FOV}=0.55$; blue circle: $\mathrm{FOV}=0$. Yellow line shows reference line used to examine image distortion and sharpness of different BTL designs by grayscale analysis. 


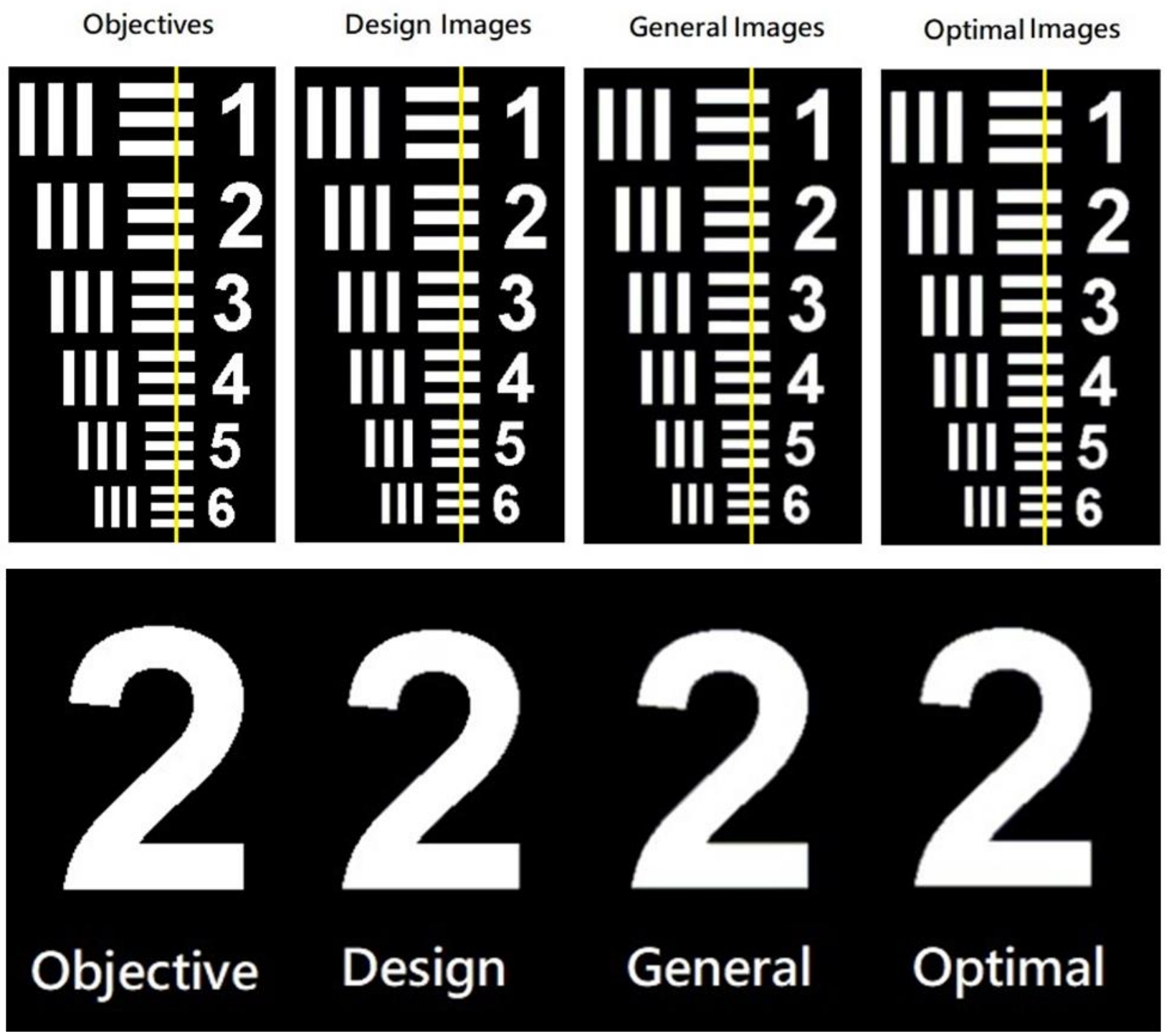

Figure 14. Two-dimensional image simulation results for the design, general, and optimal BTL models. 


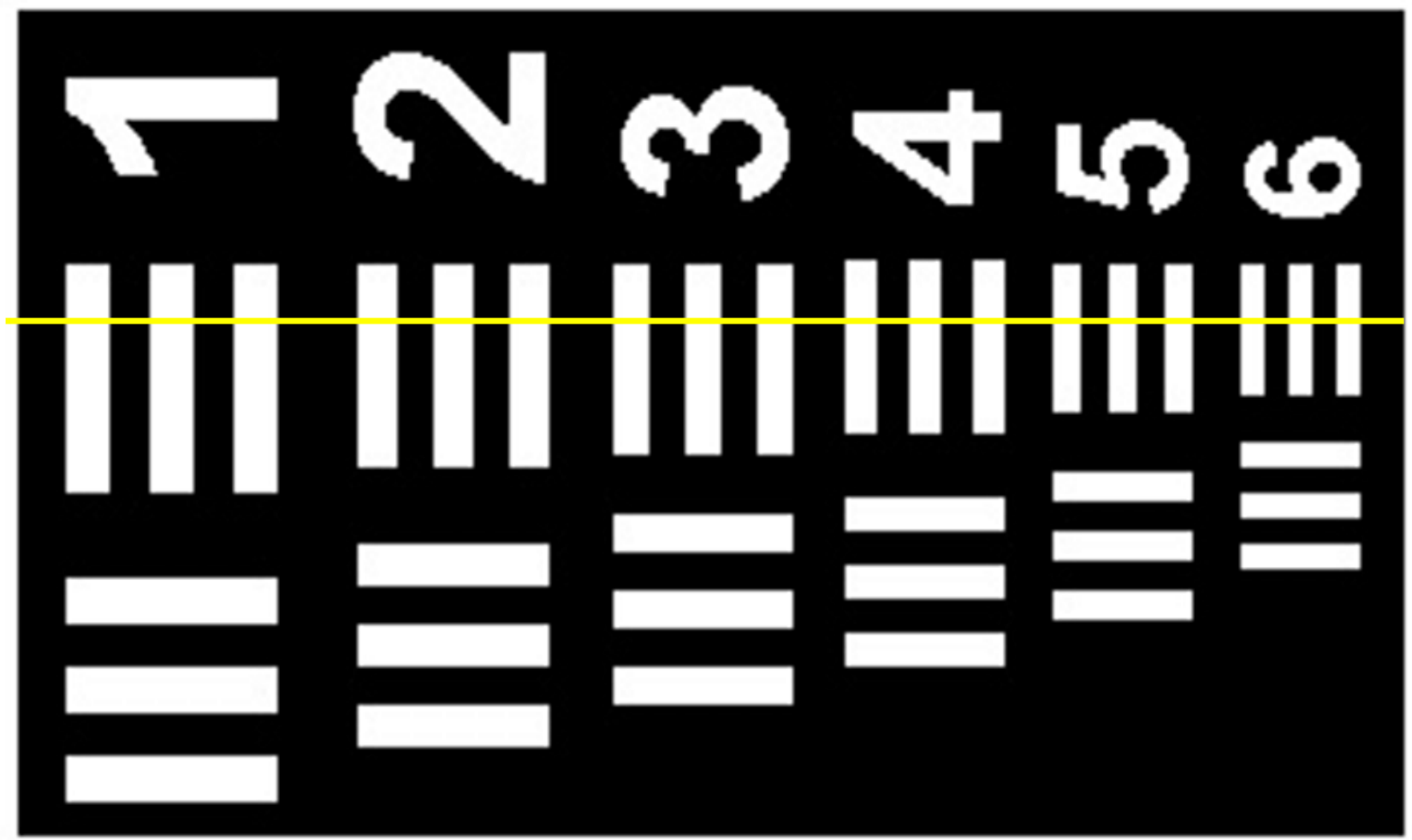

(a)

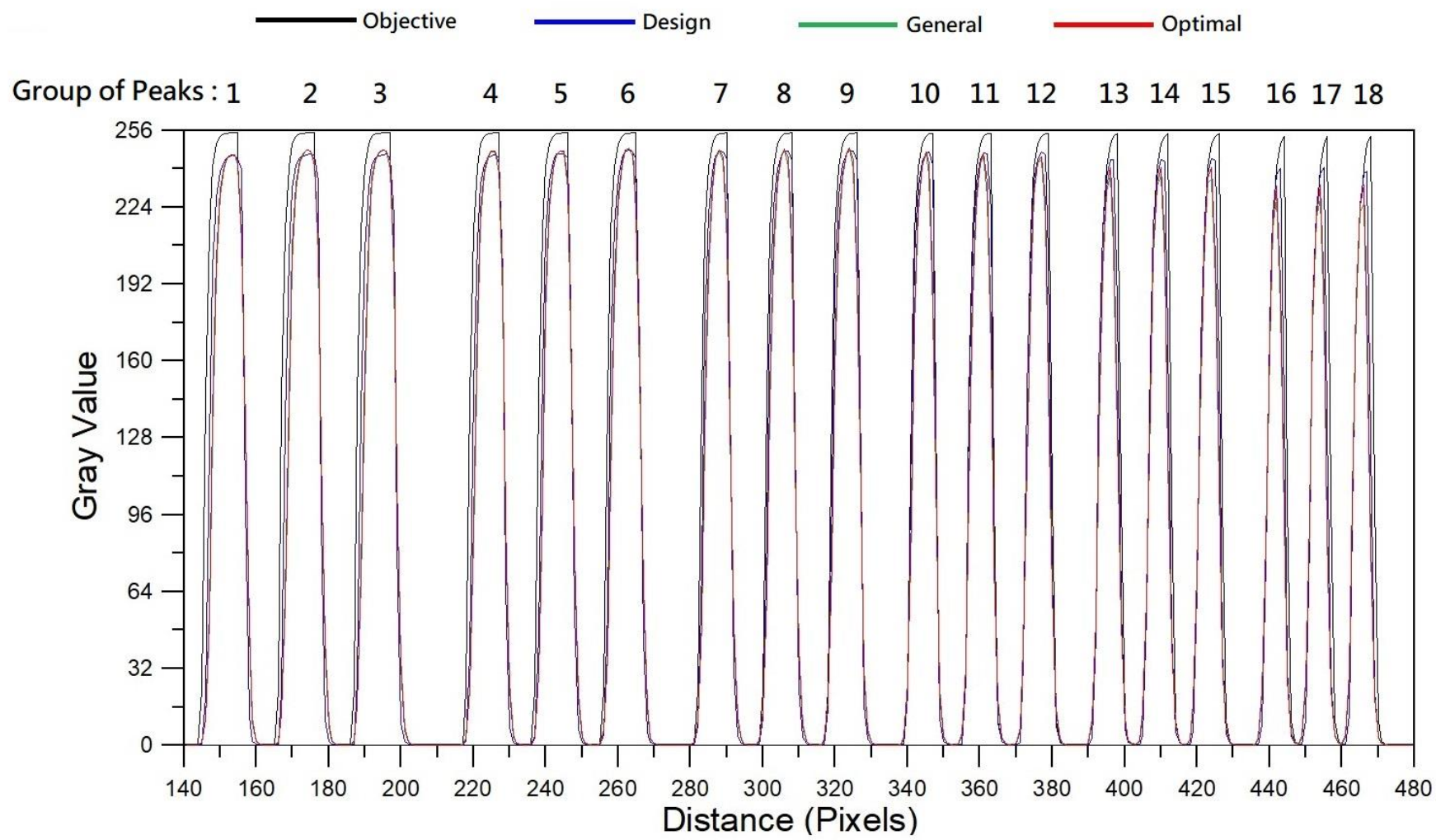

(b)

Figure 15. Quantitative image distortion and sharpness evaluation of objective, design, general, and optimal BTL models. (a) Analysis region in the USAF resolution test chart (refer to Figure 12, rotate 90 degrees counterclockwise). (b) Variation in grayscale intensity with pixel distance along yellow reference line. 


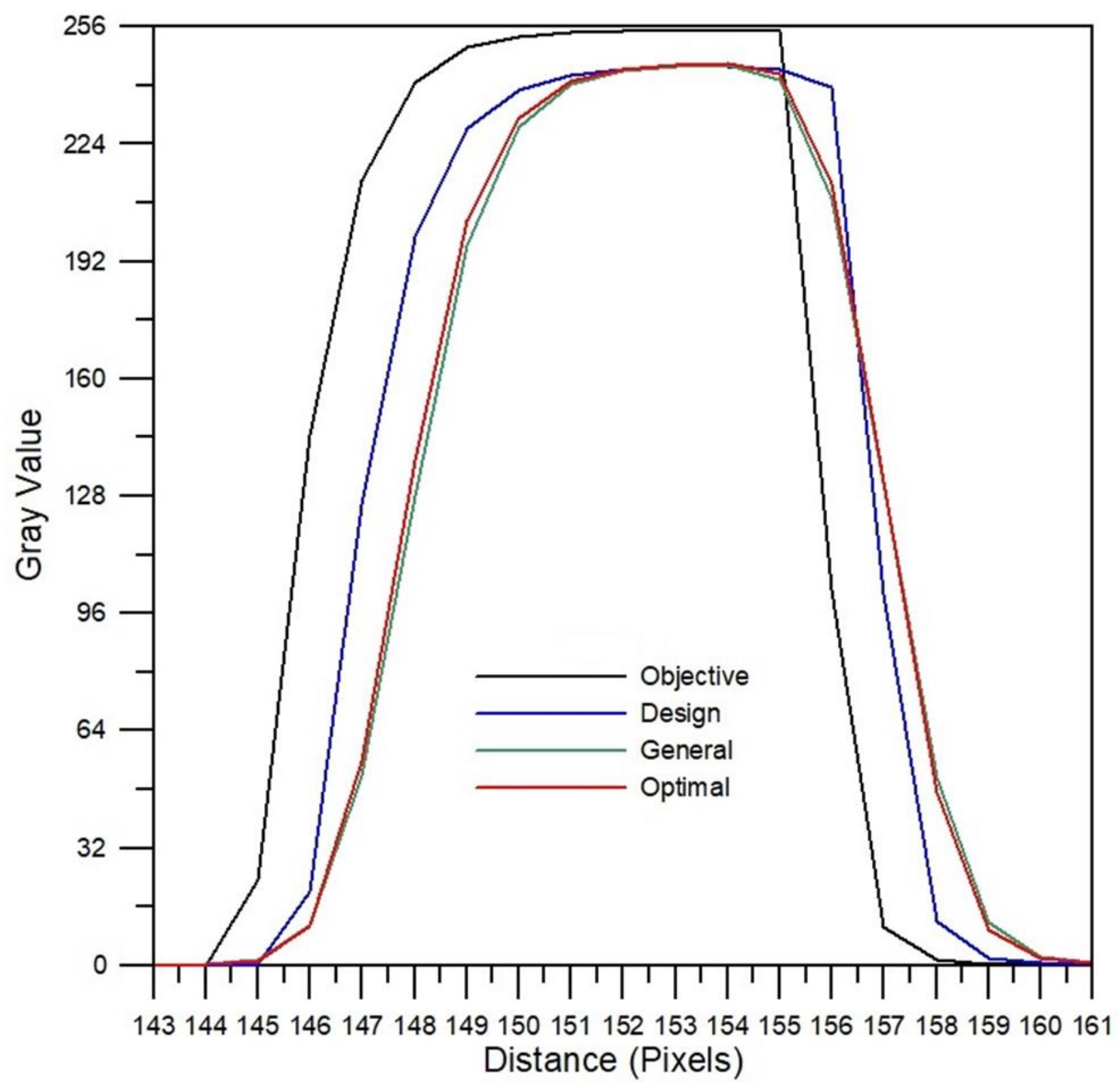

(a)

Figure 16. Cont. 


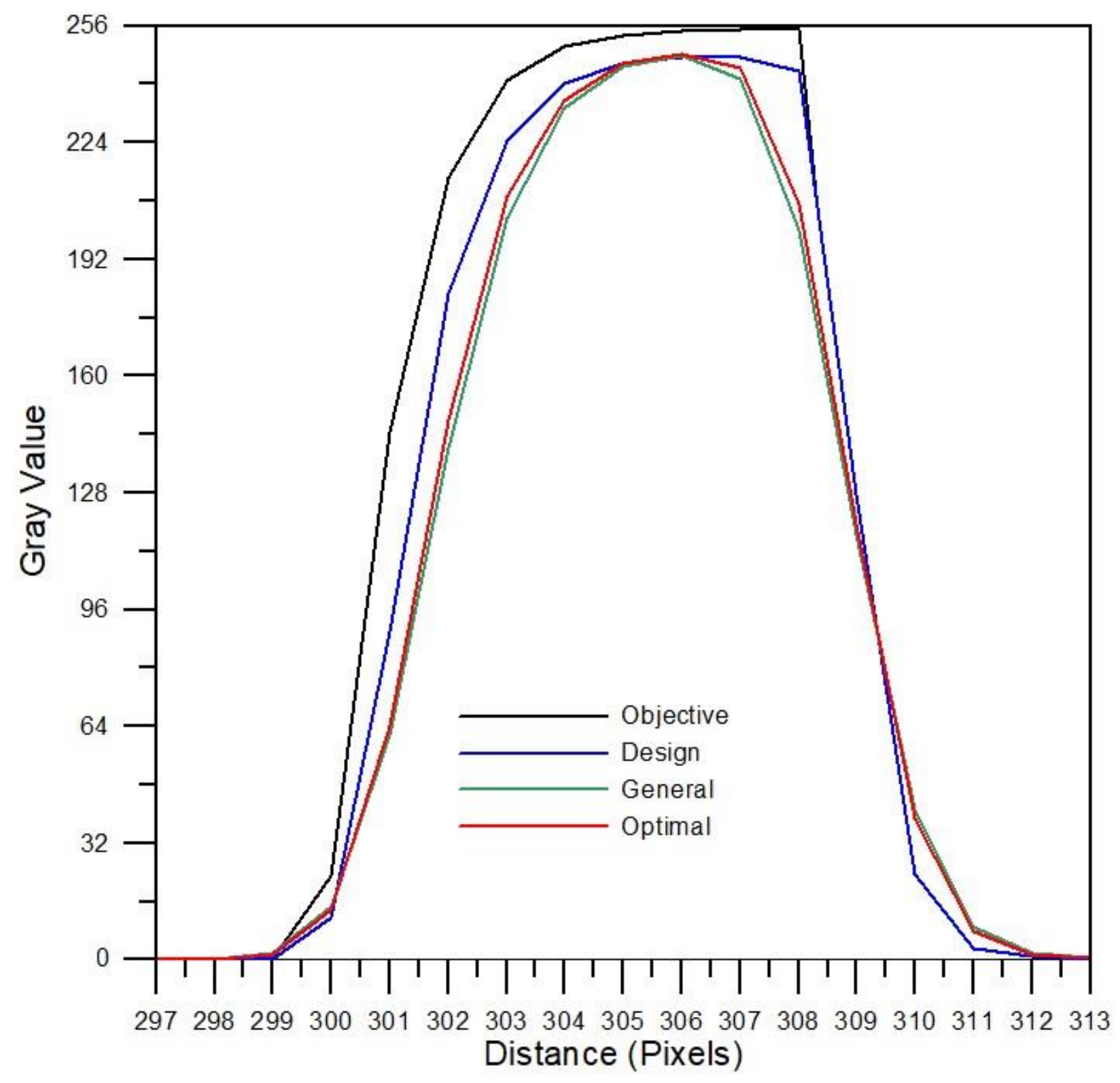

(b)

Figure 16. Cont. 


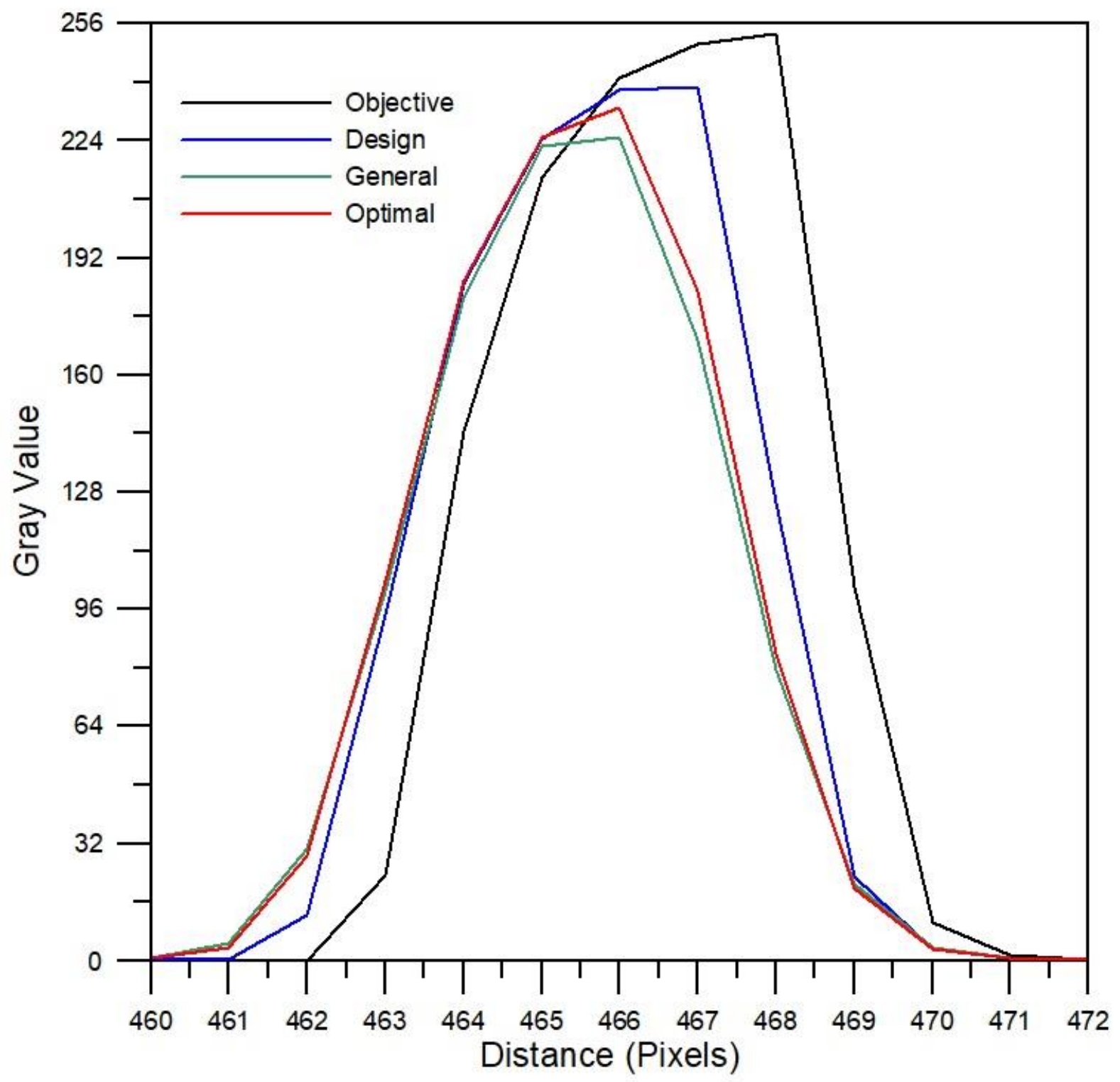

(c)

Figure 16. (a) Variation in grayscale intensity over pixel range of 143-161 (peak group 1 in Figure 15b). (b) Variation in grayscale intensity over pixel range of 297-313 (peak group 8 in Figure 15b). (c) Variation in grayscale intensity over pixel range of 460-472 (peak group 18 in Figure 15b).

Figure 16 shows that the 1st peak group is the imaging section roughly between pixel distances 143 and 161, the 8th peak group is the imaging section roughly between pixel distances 297 and 313, and the 18th peak group is the imaging section roughly between pixel distances 460 and 472 . Observing the three figures, it is clear that the design curve (i.e., the ideal BTL curve) lies closest to the objective curve in all three cases. Moreover, the optimal curve lies closer to the objective curve than the general curve in every case. In other words, the superior imaging quality of the optimized BTL design compared to the general BTL design is confirmed. For the grayscale curves shown in Figure 16a-c, a steeper gradient in the interface regions between the black and white features in the resolution test image implies a greater imaging sharpness. Thus, a detailed inspection of the grayscale analysis results for the optimal and general BTL designs confirms that the optimal design yields a better image sharpness.

The grayscale curves shown in Figure $16 \mathrm{a}-\mathrm{c}$ correspond to the upper-right, centralright, and lower-right regions of the objective image, respectively (see Figure 13). Com- 
paring the grayscale curves in the three figures, it is seen that the image distortions of the three BTL designs in Figure 16a,c are relatively large and are located to the upper right and lower right of the objective image (see Figure 13), respectively. This result is reasonable since the FOVs are quite large in both cases (i.e., $\sim 0.6$ and 0.55 , respectively) and the target geometry is not perpendicular to the direction of the FOV, resulting in a larger distortion and asymmetry, respectively. However, the grayscale curves in Figure 16b show both a smaller distortion and a greater symmetry since the FOV is smaller (i.e., 0.45 to 0.5 ) and the target geometry is perpendicular to the direction of the FOV.

\section{Conclusions}

This study combined CODE V optical analysis software, the Taguchi experimental design method, and Moldex3D flow analysis simulations to optimize the injection molding processing parameters for a bilateral telecentric lens (BTL) barrel in such a way as to maximize the coaxiality of the tube and improve the imaging performance as a result. The Taguchi analysis results show that a larger maximum packing pressure, a lower melt temperature, and a longer cooling time are all beneficial in improving the coaxiality of the BTL barrel. Moreover, the CODE V and grayscale analysis results show that the BTL barrel molded using the optimal processing conditions yields a better MTF response and focusing performance than a BTL tube molded using the general processing parameters for the chosen polymer material (PA66).

Author Contributions: Conceptualization, C.-M.L., Y.-J.C.; formal analysis, C.-M.L., Y.-J.C.; writingoriginal draft preparation, C.-M.L., Y.-J.C.; data curation, Y.-J.C.; writing-review and editing, C.-M.L.; supervision, C.-M.L.; funding acquisition, C.-M.L. All authors have read and agreed to the published version of the manuscript.

Funding: This research was funded by the Ministry of Science and Technology of Taiwan, ROC, under Grant Numbers MOST 109-2221-E-415-001-MY3 and MOST 109-2221-E-415-002-MY3.

Institutional Review Board Statement: Not applicable.

Informed Consent Statement: Not applicable.

Acknowledgments: The authors gratefully acknowledge the financial support provided to this study by the Ministry of Science and Technology of Taiwan, ROC.

Conflicts of Interest: The authors declare no conflict of interest.

\section{References}

1. Lin, C.M.; Tan, C.M.; Wang, C.K. Gate design optimization in the injection molding of the optical lens. Optoelectron. Adv. Mater. Rapid Commun. 2013, 7, 580-584.

2. Lin, C.M.; Hsieh, H.K. Processing optimization of Fresnel lenses manufacturing in the injection molding considering birefringence effect. Microsyst. Technol. 2017, 23, 5689-5695. [CrossRef]

3. Lin, C.M.; Chen, Y.W. Grey optimization of injection molding processing of plastic optical lens based on joint consideration of aberration and birefringence effects. Microsyst. Technol. 2019, 25, 621-631. [CrossRef]

4. Lu, X.; Khim, L.S. A statistical experimental study of the injection molding of optical lenses. J. Mater. Process. Technol. 2001, 113, 189. [CrossRef]

5. Lee, Y.B.; Kwon, T.H.; Yoon, K. Numerical prediction of residual stresses and birefringence in injection/compression molded center-gated disk. Part I: Basic modeling and results for injection molding. Polym. Eng. Sci. 2002, 42, 2246-2272. [CrossRef]

6. Shyu, G.D.; Isayyev, A.I.; Lee, H.S. Numerical simulation of flow-induced birefringence in injection molded disk. Jpn. Korea Plast Process Jt. Semin. 2003, 4, 41-47.

7. Fan, B.; Kazmer, D.O.; Bushko, W.C.; Theriault, R.P.; Poslinski, A.J. Birefringence prediction of optical media. Polym. Eng. Sci. 2004, 44, 814-824. [CrossRef]

8. $\quad$ Liao, S.J.; Chang, D.Y.; Chen, H.J.; Tsou, L.S.; Ho, J.R.; Yau, H.T.; Hsieh, W.H.; Wang, J.T.; Su, Y.C. Optimal process conditions of shrinkage and warpage of thin-wall parts. Polym. Eng. Sci. 2004, 44, 917-928. [CrossRef]

9. Tang, S.H.; Tan, Y.J.; Sapuan, S.M.; Sulaiman, S.; Ismail, N.; Samin, R. The use of Taguchi method in the design of plastic injection mould for reducing warpage. J. Mater. Process. Technol. 2007, 182, 418-426. [CrossRef]

10. Bociaga, E.; Jaruga, T.; Lubczynska, K.; Gnatowski, A. Warpage of injection moulded parts as the result of mould temperature difference. Arch. Mat. Sci. Eng. 2010, 44, 28-34. 
11. Shayfull, Z.; Ghazali, M.F.; Azaman, M.; Nasir, S.M.; Faris, N.A. Effect of differences core and cavity temperature on injection molded part and reducing the warpage by Taguchi method. Int. J. Eng. Technol. 2010, 10, 125-132.

12. Fischer, R.E.; Tadic-Galeb, B.; Yoder, P.R. Optical System Design, 2nd ed.; McGraw-Hill: New York, NY, USA, 2008 ; pp. 179-198.

13. Dilworth, D.C. New tools for the lens designer, Current Developments in Lens Design and Optical Engineering IX. Int. Soc. Opt. Photonics 2008, 7060, 70600B.

14. Sahin, F.E. Lens design for active alignment of mobile phone cameras. Opt. Eng. 2017, 56, 065102. [CrossRef]

15. Grabarnik, S. Optical design method for minimization of ghost stray light intensity. Appl. Opt. 2015, 54, 3083-3089. [CrossRef]

16. Sahin, F.E. Open-source optimization algorithms for optical design. Optik 2019, 178, 1016-1022. [CrossRef]

17. Houllier, T.; Lépine, T. Comparing optimization algorithms for conventional and freeform optical design: Erratum. Opt. Express 2019, 27, 28383. [CrossRef]

18. Lin, C.M.; Chen, Y.J. Taguchi Optimization of Roundness and Concentricity of a Plastic Injection Molded Barrel of a Telecentric Lens. Polymers 2021, 13, 3419. [CrossRef]

19. Sui, W.; Zhang, D. Four Methods for Roundness Evaluation. Phys. Procedia 2012, 24, 2159-2164. [CrossRef]

20. Ahn, S.J. Least Squares Orthogonal Distance Fitting of Curves and Surfaces in Space; Springer: Berlin/Heidelberg, Germany, 2004.

21. Srinivasan, V.; Shakarji, C.M.; Morse, E.P. On the enduring appeal of least-squares fitting in computational coordinate metrology. J. Comput. Inf. Sci. Eng. 2011, 12, 011008. [CrossRef]

22. Kim, N.H.; Kim, S.W. Geometrical tolerances: Improved linear approximation of least-squares evaluation of circularity by minimum variance International. J. Mach. Tools Manuf. 1996, 36, 355-366. [CrossRef]

23. Hichem, N.; Pierre, B. Evaluation of roundness error using a new method based on a small displacement screw. Meas. Sci. Technol. 2014, 25, 25.

24. O'Shea, D.C.; Bentley, J.L. Designing Optics Using CODE V; SPIE PRESS: Bellingham, WA, USA, 2018.

25. MIL-STD-150A; Military Standard: Photographic Lenses. EverySpec LLC: Gibsonia, PA, USA, 12 May 1959. 